Review

\title{
The iron L edges: Fe 2p X-ray absorption and electron energy loss spectroscopy
}

\author{
Piter S. Miedema, Frank M.F. de Groot* \\ Inorganic Chemistry and Catalysis, Utrecht University, 3584 CG Utrecht, Netherlands
}

\section{A R T I C L E I N F O}

\section{Article history:}

Received 6 September 2011

Received in revised form 13 March 2013

Accepted 14 March 2013

Available online 26 March 2013

\section{Keywords:}

X-ray absorption spectroscopy

Electron energy loss spectroscopy

Electronic structure

\begin{abstract}
A B S T R A C T
The iron L edges are reviewed. The experimental spectra obtained with 2p XAS, XMCD and 2p EELS are discussed, including isolated iron atoms, solids and coordination compounds. The largest fraction of publications deal with iron oxide systems that are discussed in detail, including binary oxides, perovskites and spinel systems. Emphasis is given on fundamental studies that focus on spectral shape analysis. We have selected a number of applications for further discussion, including iron in astrochemistry, iron complexes and nanostructures in catalysis, iron in mineralogy, the pnictide superconductors, spin crossover systems and phthalocyanine and related systems.

Some of the important theoretical concepts in the analysis of L edges are discussed, including atomic multiplet theory, crystal field theory, charge transfer theory and XMCD. The 2p XAS spectra contain much detail for halides, oxides and coordination compounds. These spectra can be analyzed in great detail, revealing much information, including the valence, the spin state and the crystal field parameters. Covalent compounds and metal alloys have spectra with much less detail, which makes analysis more difficult.
\end{abstract}

(c) 2013 Elsevier B.V. All rights reserved.

\section{Contents}

1. Introduction .

2. Atoms and ions

2.1. Theory A: atomic multiplet theory

2.2. Application I: iron in interstellar space

2.3. Small iron clusters

3. Ionic solids .

3.1. Theory B: crystal field multiplet theory

3.2. Iron fluorides.

4. Iron oxides

4.1. Theory $\mathrm{C}$ : charge transfer multiplet theory.

4.2. Binary oxides: $\mathrm{Fe}_{2} \mathrm{O}_{3}, \mathrm{Fe}_{3} \mathrm{O}_{4}$ and $\mathrm{FeO}$

4.3. Theory D: linear dichroism and XMCD .....

4.4. Iron perovskites: doping effects and $\mathrm{Fe}^{4+} \ldots$

4.5. Iron spinels: site determination from XMCD

4.6. Other iron oxides.

4.8. Application III: mineralogy

5. Iron metal alloys and covalent iron materials

5.1. Application IV: the branching ratio

5.2. Iron sulfides

5.3. Application V: Fe pnictide superconductors.

5.4. Iron metal and intermetallic alloys: XMCD and sum rules...

\footnotetext{
* Corresponding author. Tel.: +31 302537400.

E-mail addresses: f.m.f.degroot@uu.nl, degroot97a@yahoo.com (F.M.F.de Groot).
} 


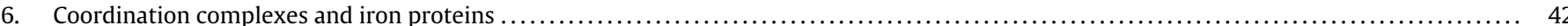

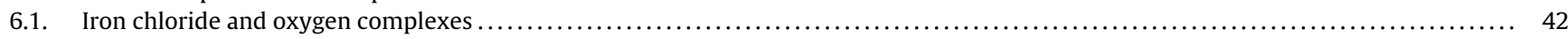

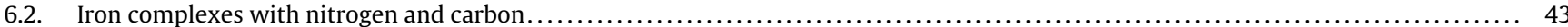

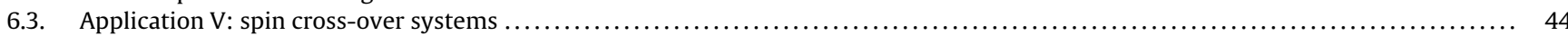

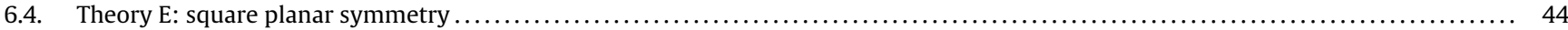

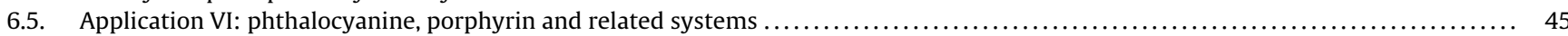

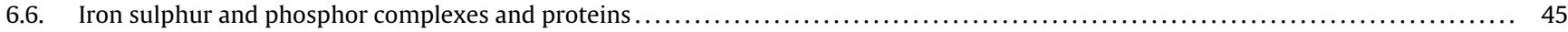

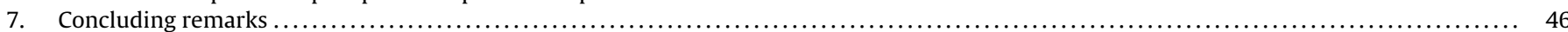

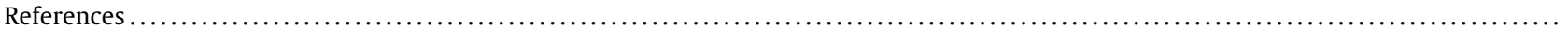

\section{Introduction}

This review discusses the iron 2p X-ray absorption spectroscopy (XAS) and Electron Energy Loss Spectroscopy (EELS) spectra of iron materials. In L edge X-ray absorption, a $2 p$ core electron is excited to an empty state. The binding energy of the $2 p$ core state of iron is approximately $710 \mathrm{eV}$. This implies that L edge XAS spectra are excited with $710 \mathrm{eV}$ soft X-rays using one of the soft X-ray beamlines at a synchrotron light source. The EELS spectra are measured with electron microscopes using a primary energy of typically 80-200 keV electron energy.

This review focuses on spectral shape analysis of the $L$ edges. We will not discuss the experimental aspects in detail and refer to papers dedicated to this topic. We assume XAS and EELS to measure an identical spectrum given by the dipole transition operator. The iron L edge XAS spectrum can be measured in transmission mode, but given the short probing depth of $710 \mathrm{eV}$ photons this is only possible for thin samples. For example, transmission X-ray microscopy (TXM) is measured in transmission mode [77]. The majority of soft XAS spectra are measured with electron yield detection or fluorescence yield detection. Yield methods detect the decay of the core hole, which gives rise to electrons and X-rays escaping from the surface of the substrate. This allows the measurement of samples with arbitrary thickness. The large interaction of electrons with matter implies that the electrons that escape from the sample originate close to the surface and the probing depth of electron yield methods is approximately $2-5 \mathrm{~nm}$. The fluorescent decay of the core hole can also be used as the basis for the XAS measurement, but only for dilute systems.

In Section 2, we discuss the 2p XAS spectrum of a free iron atom, allowing the description of the spectral shape to be limited to a single atom in spherical symmetry. Section 3 discusses ionic solids and section 4 focuses on iron oxides. Section 5 deals with covalent solids such as sulphides and metal alloys. Section 6 deals with coordination compounds, including proteins.

\section{Atoms and ions}

We start the discussion of the 2p XAS spectra of iron systems with an isolated iron atom. This allows us to explain some of the fundamental issues concerning L edges, in particular the importance of intra-atomic interactions such as the $3 \mathrm{~d} 3 \mathrm{~d}$ interactions, the $2 \mathrm{p} 3 \mathrm{~d}$ interactions and the $2 \mathrm{p}$ and $3 \mathrm{~d}$ spin-orbit coupling.

An isolated iron atom has an electronic configuration $3 d^{6} 4 s^{2}$. The ground state configuration of the six $3 d$ electrons is given by the Hunds rule. All five spin-up states are filled and the sixth electron fills the spin-down state with $m_{l}=+2$. This yields a ground state with $L=2$ and $S=2$, represented by a ${ }^{5} \mathrm{D}$ term symbol. The ${ }^{5} \mathrm{D}$ state is split into five substates by the $3 \mathrm{~d}$ spin-orbit coupling and because the $3 \mathrm{~d}$ shell is more than half full, the ground state has ${ }^{5} \mathrm{D}_{4}$ symmetry. The ground state is split into states with have, from low to high energy, the J quantum number equal to respectively $4,3,2$, 1 and 0 . The 2p X-ray absorption spectrum can be calculated by performing an atomic multiplet calculation of the final state in

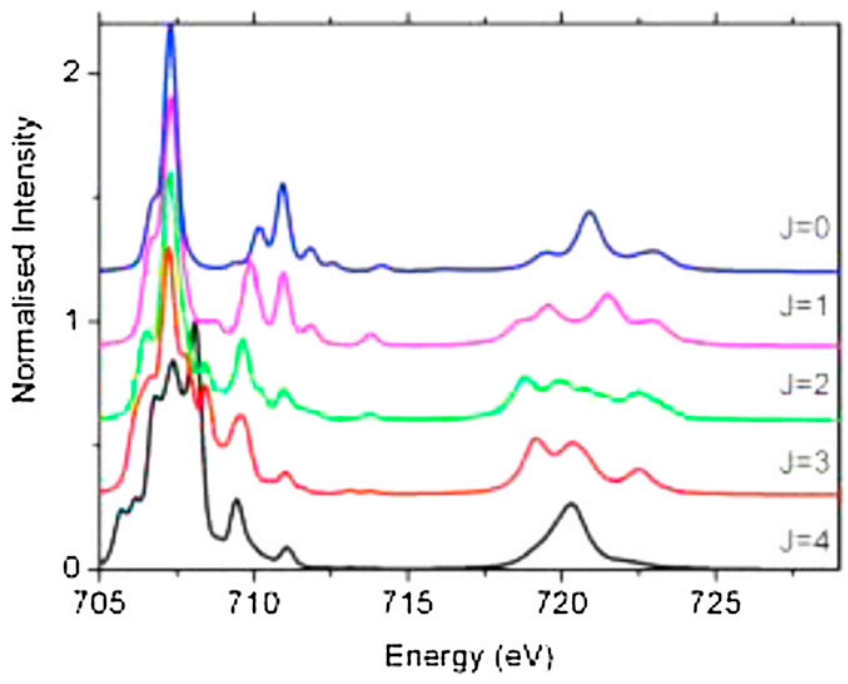

Fig. 1. the atomic multiplet calculations for the five different J-states of the ${ }^{5} \mathrm{D}$ ground state for the $3 \mathrm{~d}^{6} \rightarrow 2 \mathrm{p}^{5} 3 \mathrm{~d}^{7}$ transition.

which a $2 p$ electron has been excited to a $3 d$ state, which corresponds to a $2 \mathrm{p}^{5} 3 \mathrm{~d}^{7} 4 \mathrm{~s}^{2}$ configuration. The $2 \mathrm{p}$ spin-orbit coupling is large and splits the spectrum into its $\mathrm{L}_{3}$ and $\mathrm{L}_{2}$ components. The 2 p3d multiplet interaction, in other words the higher order interaction of the electron-electron repulsion term coupling the $2 \mathrm{p}$ and $3 \mathrm{~d}$ electronic states, is also large. The result is a large number of atomic states. Fig. 1 shows that atomic multiplet calculation for the transition $3 \mathrm{~d}^{6} \rightarrow 2 \mathrm{p}^{5} 3 \mathrm{~d}^{7}$ for the five different $\mathrm{J}$-states of the ${ }^{5} \mathrm{D}$ ground state symmetry. The relative energies of the J-states with respect to the $J=4$ ground state are respectively $54 \mathrm{meV}(J=3), 92 \mathrm{meV}(J=2)$, $116 \mathrm{meV}(J=1)$ and $128 \mathrm{meV}(J=0)$.

The theoretical spectra have been compared with the experimental 2p XAS spectrum of an iron atom [196,225]. The experimental spectrum has been measured in electron yield mode at $1750 \mathrm{~K}$. Because of this high temperature, one should calculate a Boltzmann distribution over the different $J$ substates. Fig. 2 shows the experimental 2p XAS spectrum of an iron atom, compared with the $J=4$ ground state, the spectrum calculated without $3 \mathrm{~d}$ spin-orbit coupling and the spectrum derived from a Boltzmann distribution at $1750 \mathrm{~K}$. It can be observed that the $1750 \mathrm{~K}$ spectrum reproduces the experiment, including the features at the leading edge. This experimental spectrum, as well as the $2 p$ XAS spectra of the other transition metal ions has been measured and calculated by Martins et al. [196].

The $2 \mathrm{p}$ XAS spectrum of a single iron atom on a potassium surface has been measured by Gambardella et al. [97]. They also measured the X-ray magnetic circular dichroism spectrum (XMCD), the difference between left and right polarized X-rays for a magnetized sample. Fig. 3 shows the $2 \mathrm{p}$ XAS spectra for $\mathrm{Fe}^{1-}\left(3 \mathrm{~d}^{7} 4 \mathrm{~s}^{2}\right)$, $\mathrm{Fe}^{0} / \mathrm{Fe}^{2+}\left(3 \mathrm{~d}^{6} 4 \mathrm{~s}^{2} / 3 \mathrm{~d}^{6}\right)$ and $\mathrm{Fe}^{3+}\left(3 \mathrm{~d}^{5}\right)$. The spectra for $\mathrm{Fe}^{2+}$ are equivalent to those of an iron atom $\left(\mathrm{Fe}^{0}\right)$ because the 4 s electrons do not modify the spectral shape. Both $\mathrm{Fe}^{0}$ and $\mathrm{Fe}^{2+}$ have a ${ }^{5} \mathrm{D}_{4}$ ground 


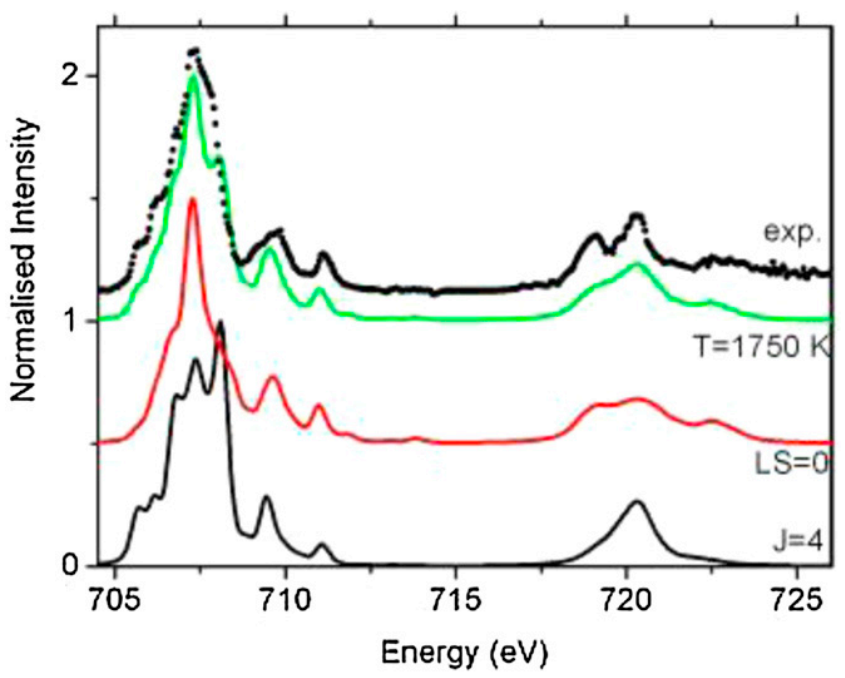

Fig. 2. The atomic multiplet calculations for ${ }^{5} \mathrm{D}_{4}$ ground state (bottom), the averaged spectrum for the five J-states (middle) and the spectrum calculated at $1750 \mathrm{~K}$ using a Boltzmann distribution (top, solid). The $1750 \mathrm{~K}$ spectrum is compared with the experiment $2 \mathrm{p}$ XAS spectrum of an iron atom.

Digitized from [196].

state symmetry. Fig. 3 shows both the ${ }^{5} \mathrm{D}_{4}$ ground state and the high-temperature case of equal occupation of all ${ }^{5} \mathrm{D}$ states. In case of a $3 d^{7}$ ground state, the ${ }^{4} \mathrm{~F}$ ground state symmetry is split by the $3 d$ spin-orbit coupling into states with $J=9 / 2,7 / 2,5 / 2$ and $3 / 2$. Fig. 3 shows the ${ }^{4} \mathrm{~F}_{9 / 2}$ ground state and the averaged ${ }^{4} \mathrm{~F}$ spectrum. The excited J-states of a $3 d^{7}$ ground state are partially occupied if the measurements are performed at finite temperatures. The $\mathrm{Fe}^{3+}$ $3 \mathrm{~d}^{5}$ ground state has no orbital moment; hence its $J$ value is equal to its $S$ value. The ${ }^{6} S_{5 / 2}$ ground state is given in blue. The XAS and XMCD spectrum of the $\mathrm{Fe}($ atom)/K system corresponds closely to the atomic multiplet spectrum of a $3 \mathrm{~d}^{7}$ ground state, suggesting an $\mathrm{Fe}^{1-}$ ground state configuration [97].

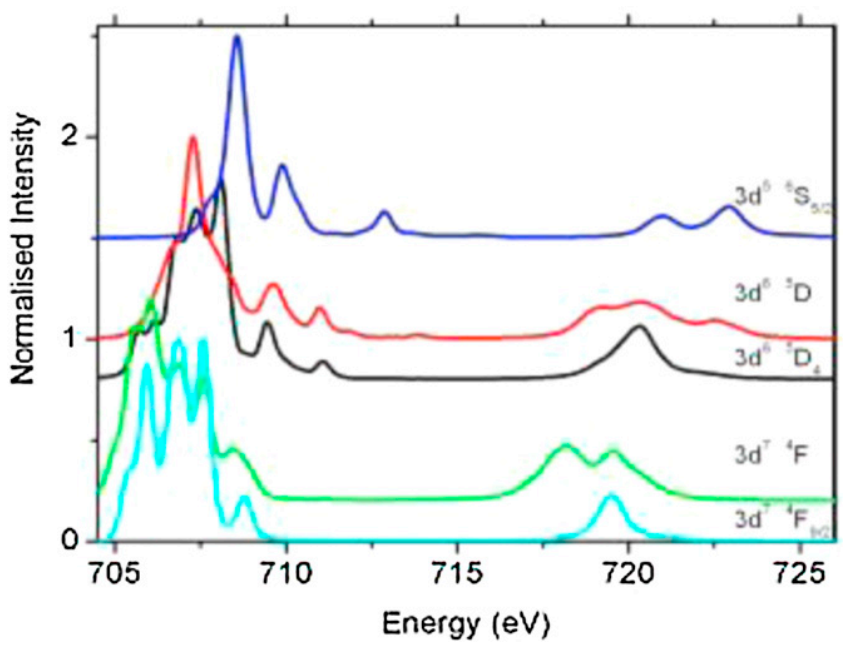

Fig. 3. The atomic multiplet calculations for $\mathrm{Fe}^{1+}, \mathrm{Fe}^{2+}$ and $\mathrm{Fe}^{3+}$ ions. From top to bottom are given: The $\mathrm{Fe}^{3+} 3 \mathrm{~d}^{5}{ }^{6} \mathrm{~S}_{5 / 2}$ ground state (blue), the $\mathrm{Fe}^{2+} 3 \mathrm{~d}^{6}{ }^{5} \mathrm{D}$ ground state (red), the same ground state with spin-orbit coupling $\left({ }^{5} \mathrm{D}_{4}\right)$ (black), the $\mathrm{Fe}^{1+}$ $3 d^{7}{ }^{4} \mathrm{~F}$ ground state (green), the same ground state with spin-orbit coupling $\left({ }^{4} \mathrm{~F}_{9 / 2}\right)$ (blue). (For interpretation of the references to color in this figure legend, the reader is referred to the web version of the article.)

\subsection{Theory A: atomic multiplet theory}

X-ray absorption spectra of free atoms can be described with atomic multiplet theory. Atomic multiplet theory uses quantum mechanics to solve the atomic Hamiltonian that describes the ground state and the core excited states on an iron atom. The electronic energy states in an atom are given by a combination of four interactions:

a) The nuclear energy due to the attraction between the nucleus and the electrons. The nucleus has a positive charge that yields a deep spherical potential well. In this potential well, the electrons are bound into their quantum chemical states.

b) The kinetic energy of the electrons describe the motion of the electrons in their atomic states.

c) The electron-electron interaction describes the repulsion between the electrons.

d) The spin-orbit coupling is small compared with the other three interactions.

The Hamiltonian is usually divided into large energy terms consisting of the kinetic energy, the nuclear energy and the spherical averaged electron-electron interaction. Together these three interactions determine the energy of a certain configuration. The remaining two smaller energy effects, i.e. the non-spherical electron-electron interaction and the spin-orbit coupling determine the splitting of the states (indicated with term symbols) within a certain electron configuration. This splitting of a certain $3 \mathrm{~d}^{\mathrm{n}}$ is indicated as multiplet splitting. The ground state is given by the Hunds rules, (1) maximum S, (2) maximum L and (3) maximum $\mathrm{J}$, if the shell is more than half-full which is the case for the common iron valences $\mathrm{Fe}^{2+}$ and $\mathrm{Fe}^{3+}$.

The $3 \mathrm{~d}^{6}$ ground state has, as discussed above, $S_{\max }=2, L_{\max }=2$, $J_{\max }=4$ or a ${ }^{5} \mathrm{D}_{4}$ ground state. From the $J=4$ ground state, the $J^{\prime}=3$ or 4 or 5 final states within the $2 \mathrm{p}^{5} 3 \mathrm{~d}^{7}$ manifold can be reached with the dipole selection rule. This relates to respectively 24,18 and 11 states. In total the atomic multiplet spectrum from a ${ }^{5} \mathrm{D}_{4}$ ground state has 53 different final state energies. After broadening the atomic multiplet spectrum as given in Fig. 3 is found. The $3 d^{5}$ ground state has a ${ }^{6} \mathrm{~S}_{5 / 2}$ ground state with transitions to $35\left(J^{\prime}=3 / 2\right)$ plus $39\left(J^{\prime}=5 / 2\right)$ plus $36\left(J^{\prime}=7 / 2\right)$ final states.

For more details regarding the use of atomic multiplet theory in X-ray absorption spectroscopy, we refer to The Theory of Atomic Structure and Spectra [62], the Hitchhiker's guide to multiplet calculations [271] and Core Level Spectroscopy of Solids [74]. The atomic multiplet Hamiltonian can be solved using the Relativistic Hartree-Fock (RHF) approach and Cowan has shown that many atomic spectra can be well simulated by using a RHF with scaled parameters for the electron-electron interactions. To take into account the intra-atomic configuration interaction with a large number of weakly perturbing states, the Coulomb integrals have been scaled down to $80 \%$ of their ab initio values. This slightly reduces the multiplet splitting, which is overestimated otherwise. The calculations have been performed with the CTM4XAS interface [244].

\subsection{Application I: iron in interstellar space}

X-ray detectors on the satellites Chandra and XMM-Newton can measure X-ray absorption and emission spectra from $200 \mathrm{eV}$ to $8000 \mathrm{eV}[179,138,181]$. As such, these detectors are sensitive to space plasma in atomic and condensed matter forms and the elemental spectra that can be detected range from the carbon $\mathrm{K}$ to the iron $\mathrm{K}$ edge. The main elements that are found are carbon, oxygen, silicon and iron. Astrophysicists have reported on the detections of ions in a variety of space environments ranging from 


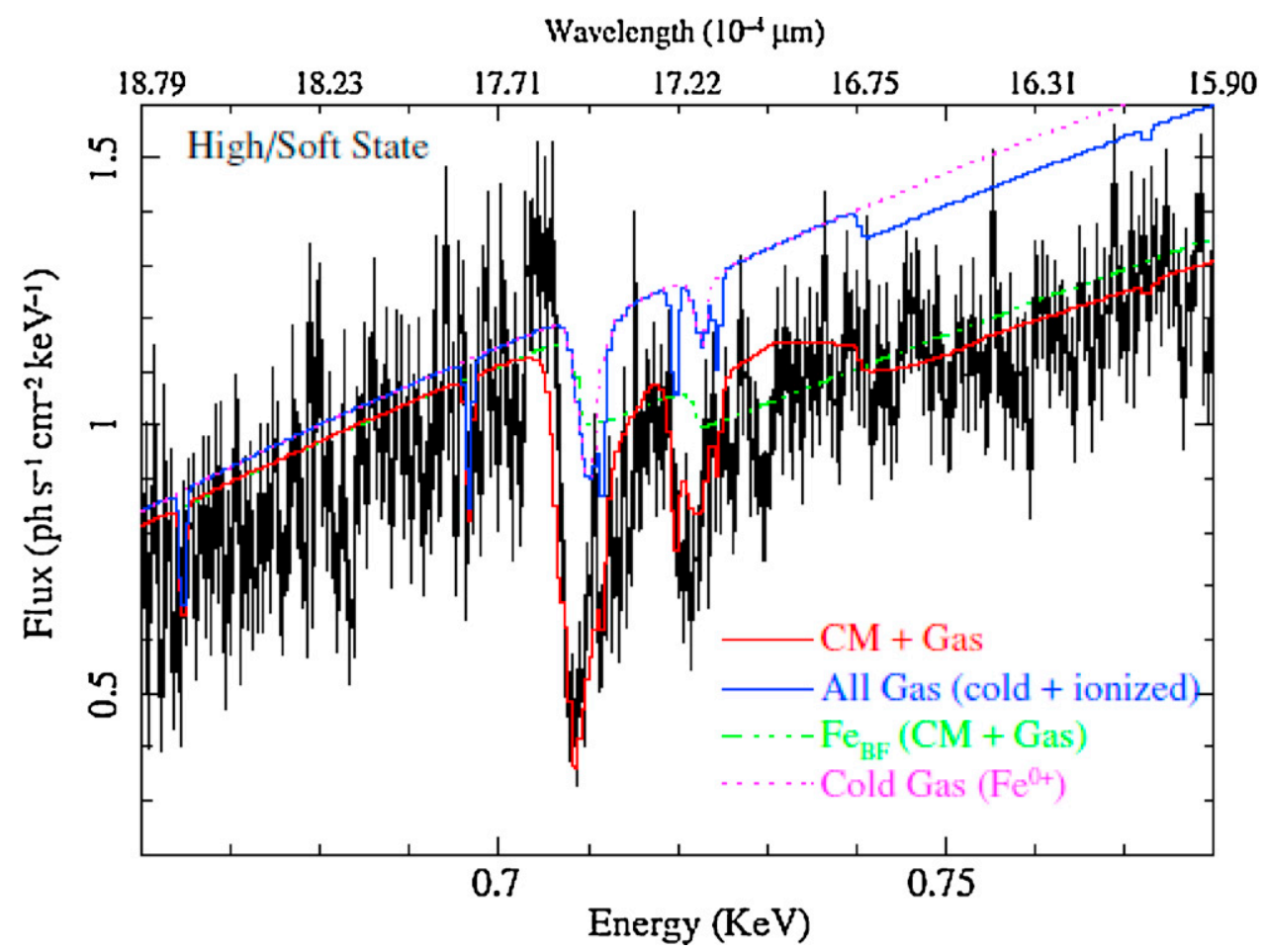

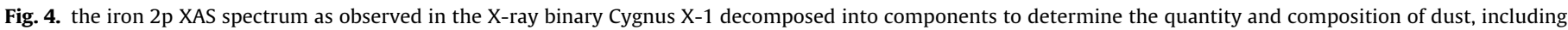
condensed matter (CM) and gas phase fractions [181].

cold (few $\mathrm{K}$ ) interstellar space to hot $\left(10^{7} \mathrm{~K}\right)$ regions near black holes. X-rays, e.g. emitted by black holes, can be used as a powerful tool to measure both the quantity and composition of cosmic dust in a variety of space environments given enough opacity and signal-to-noise [181,182]. Fig. 4 shows the iron K edge of the X-ray binary Cygnus X-1 [181]. Recent experiments yield spectra with an improved resolution, revealing that iron is surrounded by sulfur (Lee, submitted).

\subsection{Small iron clusters}

Transition metal clusters are important model systems to study the evolution of magnetic and electronic properties from single atoms to bulk metals [128]. According to Hunds rules, magnetic moments are maximized in free atoms. In bulk metals, the spin moments are weakened, leaving only iron, cobalt, and nickel as ferromagnetic elements at room temperature. In addition, the orbital magnetic moment is quenched by the crystal field. In Stern-Gerlach experiments on cluster beams, small clusters have been shown to exhibit super-paramagnetic behavior. Their magnetic moments are enhanced over the respective bulk values and show significant sizedependent variations. The bulk values of the magnetic moments are approached only for clusters of several hundred atoms. Similar enhancements were also found in theoretical studies of small iron clusters, ad-atoms, nanostructures and monolayers. Magnetic properties of free as well as supported clusters and nanostructures are receiving considerable interest due to advances in both experimental and theoretical techniques.

Lau et al. [175] measured the Fe 2p XAS spectra of small iron clusters on $\mathrm{Ni} / \mathrm{Cu}(001)$ surfaces. The $2 \mathrm{p}$ XAS spectrum of the $\mathrm{Fe}_{7}$ cluster looks similar to the spectrum of bulk iron metal, indicating that small metal clusters already lose their atomic behavior. From the XMCD spectra, analyzed with sum rules, the cluster size dependence of the orbital and spin magnetic moments have been extracted. The ratio of orbital to spin magnetic moments varies with cluster size, enhanced orbital moments in the smallest clusters.

\section{Ionic solids}

Ionic solids are strongly affected by atomic multiplet effects in combination with solid state effects. It turns out that ionic solids can be well treated with crystal field theory and the crystal field multiplet model is used for simulations and fitting of their X-ray absorption spectra. In this section, we limit ourselves to halides and show that they can be simulated in detail with crystal field multiplet theory.

\subsection{Theory B: crystal field multiplet theory}

Crystal field theory can be considered as an extension of the classical electrostatic considerations of ionic interactions. The electrostatic theory is based on the assumption that the central metal ion and its surrounding ions or ligands are kept together by ion-ion or ion-dipole electrostatic interactions. The bulk fluorides can be considered as ionic systems and therefore should be well described with crystal field multiplet theory. The starting point of crystal field multiplet theory is the approximation that the transition metal is an isolated ion with its electronic structure surrounded by a distribution of structure-less point charge sources, which mimic the symmetry around the central ion. Excellent textbooks on crystal field theory include Spectroscopy of Transition-Group Complexes [137] and Ligand Field Theory and the Properties of Transition Metal Complexes [186]. A recent review is Inorganic and Bioinorganic Spectroscopy [239].

The effect of the cubic crystal field is that the five $3 \mathrm{~d}$ orbitals will lose their degeneracy and become split in energy, where the energy splitting is $10 \mathrm{Dq}$, into two distinct representations of $t_{2 g}$ and $e_{g}$ symmetry. The 2 -fold degenerate $e_{g}$ state contains orbitals that point toward the center of the cube faces, which is directly toward the position of the ligands. Consequently, $\mathrm{E}_{\mathrm{g}}$ states interact stronger with the ligands. The three $t_{2 g}$ orbitals point toward the corners of the cube, and therefore, their interaction with the octahedral ligands is smaller. Fig. 5 shows the crystal field splitting in 


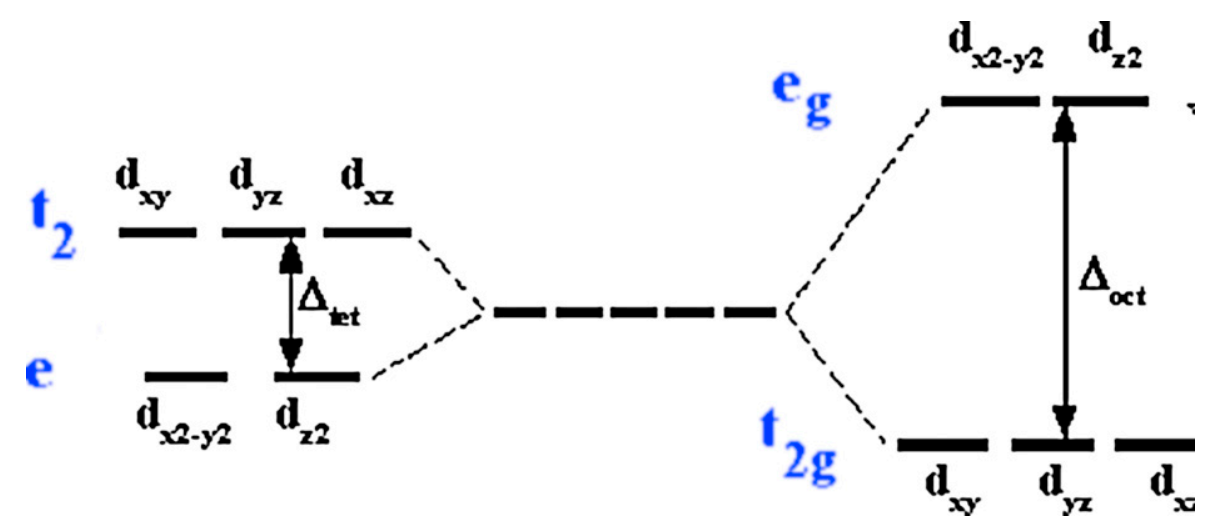

Fig. 5. d-Orbital splitting in tetrahedral (left) and octahedral (right) surroundings.

octahedral $\left(\Delta_{\text {oct }}=10 \mathrm{Dq}\right)$ and tetrahedral symmetry. In tetrahedral symmetry, as well as in 8-fold cubic symmetry, the crystal field splitting $\left(\Delta_{\text {tet }}=-10 \mathrm{Dq}\right)$ is reversed and the e orbitals have a lower energy than the $t_{2}$ orbitals. Because tetrahedral symmetry breaks the inversion symmetry, the gerade $(\mathrm{g})$ label is removed.

Depending on the energy difference of the $e_{g}$ and $t_{2 g}$ states, high- and low-spin states may be observed for $3 d^{4}-3 d^{7}$ metal ions. Consider a $3 d^{4}$ ground state. The first three electrons fill the $t_{2 g}$ shell. The fourth electron can also fill the $t_{2 g}$ electron, but has to be spin-down in character. Instead it can fill an eg orbital. This costs the crystal field energy 10Dq, but yields three times the exchange energy $\mathrm{J}$ between the spin-up electrons. The relative energies of $10 \mathrm{Dq}$ and $3 \mathrm{~J}$ determine if the fourth electron fills the $\mathrm{e}_{\mathrm{g}}$ state (highspin) or the $t_{2 g}$ state (low-spin). One can check that a $3 d^{5}$ system will have the same energy criterion and that for $3 d^{6}$ and $3 d^{7}$ systems one has to compare $10 \mathrm{Dq}$ with $2 \mathrm{~J}$. All other $3 \mathrm{~d}$ counts are always high-spin in octahedral symmetry. Lower symmetries are discussed in Section 6.4.

In 2p X-ray absorption, crystal field theory acts on the atomic multiplet states. This is similar to crystal field theory for ddtransitions. In fact, the ground state is described from a $3 \mathrm{~d}^{n}$ configuration with atomic multiplets and crystal field effects. Traditionally, these effects are shown in a Tanabe-Sugano diagram showing all configurations. In $2 p$ XAS, we only need to know the lowest energy configuration and then calculate the transition to the $2 \mathrm{p}^{5} 3 \mathrm{~d}^{n+1}$ final states. Because the $2 \mathrm{p}$ core hole spin-orbit coupling is large, one cannot use LS coupling and always acts with the crystal field on the J quantum numbers from atomic multiplet theory $[69,73]$.

Fig. 6 shows the transition from atomic to octahedral symmetry for a $3 d^{6}$ system. The ${ }^{5} \mathrm{D}$ ground state is split by the $3 \mathrm{~d}$ spin-orbit coupling into its five $\mathrm{J}$ components. A finite $10 \mathrm{Dq}$ value splits the atomic $\mathrm{J}$ states according to the $\mathrm{SO}_{3}>\mathrm{O}_{\mathrm{h}}$ branching rules. The $J=4$ state splits into $T_{2}, E, T_{1}$ and $A_{1}$. The $J=3$ state into $T_{1}, T_{2}$ and $A_{2}$ and the $J=2$ state into $\mathrm{E}$ and $\mathrm{T}_{2}$. The $J=1$ state and the $J=0$ state do not split and are transformed into respectively $\mathrm{T}_{1}$ and $\mathrm{A}_{1}$ symmetry. One can observe that the octahedral crystal field form two groups of states, respectively the ${ }^{5} \mathrm{~T}_{2 \mathrm{~g}}$ group and the ${ }^{5} \mathrm{E}_{\mathrm{g}}$ group. The reason is that the crystal field acts on the orbital moment and the $\mathrm{D}$ ground state splits into $\mathrm{T}_{2}$ and $\mathrm{E}$ sub-states. The ${ }^{5} \mathrm{~T}_{2 \mathrm{~g}}$ group contains six different states after spin-orbit coupling. Four states originate from the ${ }^{5} D_{4}$ state and two from the ${ }^{5} D_{3}$ state. Only states with identical symmetry mix and one can observe the mixing of the three $T_{2}$ states (dark blue) that originate from ${ }^{5} \mathrm{D}_{4},{ }^{5} \mathrm{D}_{3}$ and ${ }^{5} \mathrm{D}_{2}$. The crystal field mixes these states and the three $\mathrm{T}_{2}$ states are linear combinations of their three atomic components.

The $3 \mathrm{~d}$ spin-orbit coupling than splits these states into their sub-states as indicated in the figure. We will find that in some systems, the $3 \mathrm{~d}$ spin-orbit coupling is quenched. In that case all the
Table 1

The 2pXAS and 2pEELS papers of iron fluorides. This table is an extract from the full table that is maintained at the XASEELS database website (2010). Iron chloride coordination compounds are included in Table 7.

\begin{tabular}{ll}
\hline \multicolumn{2}{l}{ Iron fluoride 2p XAS and 2p EELS spectra } \\
\hline $\mathrm{FeF}_{2}$ & [51] XAS $-[279]$ EELS $-[155]$ XAS $-[187]$ EELS $-[208]$ XAS \\
$\mathrm{FeF}_{3}$ & {$[275]$ XAS $-[187]$ EELS } \\
$\mathrm{FeCl}_{3}$ & {$[260]$ XAS } \\
$\mathrm{Fe}^{2+/ 3+}$ & {$[114]$ CALC $-[287]$ CALC $-[68]$ CALC $-[269]$ CALC $-[64]$ CALC } \\
& $-[253]$ CALC \\
\hline
\end{tabular}

sub-states coincide to a single ${ }^{5} \mathrm{~T}_{2 \mathrm{~g}}$ state and a single ${ }^{5} \mathrm{E}_{\mathrm{g}}$ state. If one increases the crystal field value beyond $0.1 \mathrm{eV}$ the two groups of states will remain in similar fashion as for $0.1 \mathrm{eV}$. The spin-orbit coupling effect on the ${ }^{5} \mathrm{E}_{\mathrm{g}}$ state will decrease further. With a crystal field of $1.0 \mathrm{eV}$, the spin-orbit spread of the ${ }^{5} \mathrm{E}_{\mathrm{g}}$ state is only $1.3 \mathrm{meV}$, while it is $65.0 \mathrm{meV}$ for the $\mathrm{T}_{2 \mathrm{~g}}$ state. The reason is that the $3 \mathrm{~d}$ spin-orbit coupling acts only in second order on $\mathrm{E}_{\mathrm{g}}$ states, implying that an $\mathrm{E}_{\mathrm{g}}$ ground state is likely to have a quenched $3 \mathrm{~d}$ spin-orbit coupling, in contrast to a $\mathrm{T}_{2 \mathrm{~g}}$ ground state. Because high-spin $\mathrm{Fe}^{2+}$ in octahedral symmetry has a $\mathrm{T}_{2 \mathrm{~g}}$ ground state, it can be expected that the effects of $3 d$ spin-orbit coupling are significant. An overview of crystal field multiplet calculations is given in Table 1 .

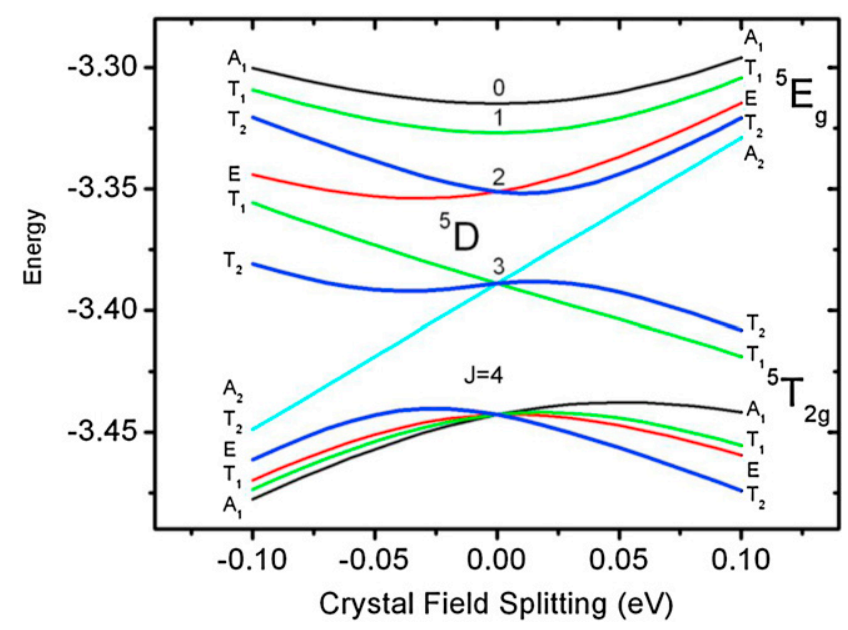

Fig. 6. the Tanabe-Sugano diagram of the relative energies of the ${ }^{5} \mathrm{D}$ states as a function of the crystal field splitting. At zero splitting the atomic ${ }^{5} \mathrm{D}_{4},{ }^{5} \mathrm{D}_{3},{ }^{5} \mathrm{D}_{2},{ }^{5} \mathrm{D}_{1}$ and ${ }^{5} D_{0}$ states are found, indicated with $J=4$ and subsequently $3,2,1$ and 0 . The crystal field splits these states into two manifolds, the ${ }^{5} \mathrm{~T}_{2 g}$ states and the ${ }^{5} \mathrm{E}_{\mathrm{g}}$ states for positive crystal field splitting. For negative crystal field splitting it is ${ }^{5} \mathrm{~T}_{2}$ and ${ }^{5} \mathrm{E}$ (but then reversed in energy). 

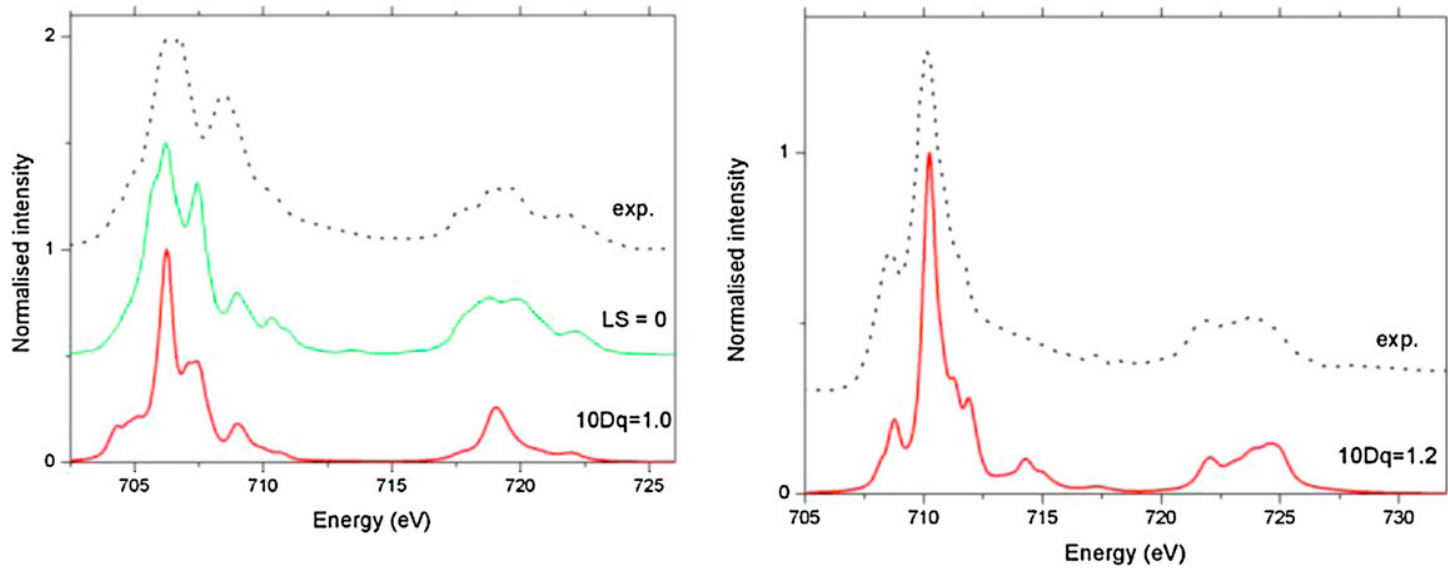

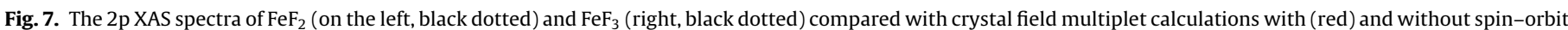
coupling (green). (For interpretation of the references to color in this figure legend, the reader is referred to the web version of the article.)

\subsection{Iron fluorides}

The iron fluorides are the most ionic iron compounds and they should be well described by crystal field multiplet theory. Fig. 7 shows the 2p XAS spectrum of $\mathrm{FeF}_{2}$ simulated using a crystal field multiplet calculation with $10 \mathrm{Dq}=1.0 \mathrm{eV}$ with and without spin-orbit coupling [51]. It is noticed that iron di-fluoride is better described without $3 \mathrm{~d}$ spin-orbit coupling, in particular at the $\mathrm{L}_{2}$ edge. $\mathrm{FeF}_{2}$ has the rutile crystal structure and the low-symmetry effectively quenches the spin-orbit splitting. A more detailed calculation would have to take into account the symmetry reduction. The 2 p XAS spectrum of $\mathrm{FeF}_{3}[155,275]$ is simulated by using an octahedral crystal field of $1.2 \mathrm{eV}$. The ${ }^{6} \mathrm{~A}_{1}$ ground state of the $\mathrm{Fe}^{3+}$ ion is not affected by $3 \mathrm{~d}$ spin-orbit coupling. The iron chloride coordination complexes, for example $\mathrm{FeCl}_{42}^{-}$, are discussed in Section 6.1.

\section{Iron oxides}

Iron oxides are an important class of materials for a large range of research fields and applications, including catalysis, batteries, magnetic and electric solids/devices. Iron and oxygen are two of the most abundant elements on earth and as such the study of iron oxides is of central importance in mineralogy (Fig. 8). In addition to the binary oxides, also the combined oxides with other abundant elements, $\mathrm{Si}, \mathrm{Al}$ and $\mathrm{Mg}$ are important. $\mathrm{LaFeO}_{3}$ and related

\section{(a) $\mathrm{FeO}$}

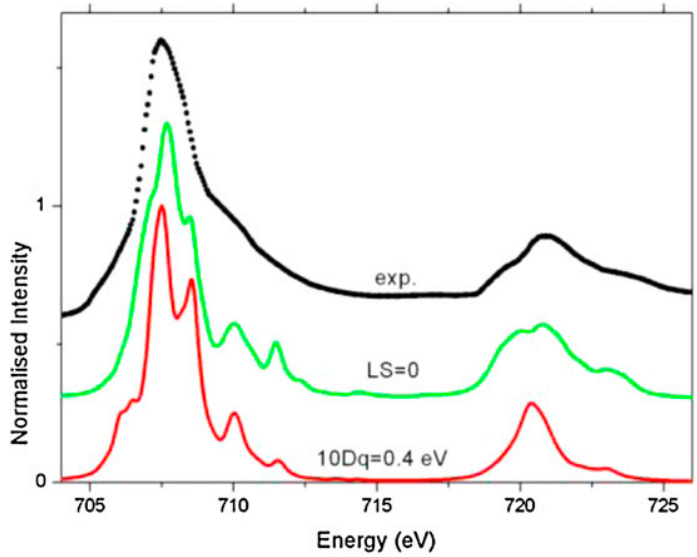

perovskites are studied heavily for their superconducting $(\mathrm{Cu})$ and giant magnetoresistance (Mn) properties. Another class of important magnetic oxides are the mixed transition metal spinel systems. Before we start with the discussion of binary iron oxides, $\mathrm{Foe}, \mathrm{Fe}_{2} \mathrm{O}_{3}$ and $\mathrm{Fe}_{3} \mathrm{O}_{4}$, we first introduce charge transfer multiplet theory. Iron oxides cannot be described in full with crystal field multiplet theory. The chemical bonds with oxygen are too covalent to be well described with an ionic model.

\subsection{Theory C: charge transfer multiplet theory}

X-ray absorption spectra in covalent solids such as bulk oxides need the addition of more than one configuration. The charge transfer method is based on the Anderson impurity model and describes a localized state, the $3 \mathrm{~d}^{n}$ state, which interacts with delocalized electrons in bands. Crystal field multiplet calculations use one $3 \mathrm{~d}^{n}$ configuration for which it solves the effective atomic Hamiltonian plus the crystal field Hamiltonian. One can combine this configuration with other low-lying configurations similar to the way configuration-interaction works with a combination of Hartree-Fock matrices. The basic charge-transfer model adds a configuration $3 \mathrm{~d}^{n+1} \mathrm{~L}$ to the $3 \mathrm{~d}^{n}$ ground state. In the case of a transition-metal oxide, in a $3 \mathrm{~d}^{n+1}$ Lconfiguration an electron has been moved from the oxygen $2 \mathrm{p}$ valence band to the metal $3 \mathrm{~d}$ band and the $\underline{L}$ represents a ligand hole. The energy difference between

\section{(b) $\alpha-\mathrm{Fe}_{2} \mathrm{O}_{3}$}

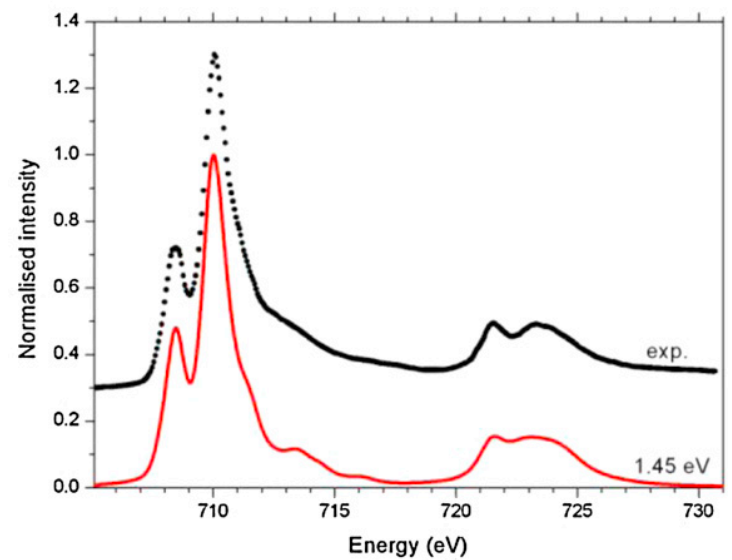

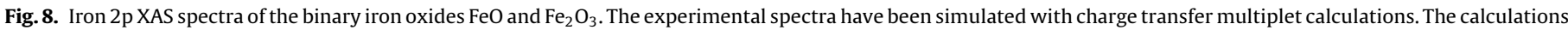
are carried out in octahedral symmetry. (For interpretation of the references to color in text, the reader is referred to the web version of the article.) 
the $3 \mathrm{~d}^{n}$ and $3 \mathrm{~d}^{n+1} \underline{\mathrm{L}}$ configurations is the so-called charge-transfer energy.

One can continue this procedure and add a $3 \mathrm{~d}^{n+2} \underline{L}^{2}$ configuration etc. In many cases, however, two configurations will be enough to explain the spectral shapes, but in particular for high valence states, it may become important to include more configurations. In principle, also the reverse charge transfer effect can be studied by adding a $3 \mathrm{~d}^{n-1} \mathrm{~L}$ configuration, where $\mathrm{L}$ represents an extra electron in a ligand valence band. This is important for molecular systems with strong $\pi$-bonds, discussed in Section 6.2.

\subsection{Binary oxides: $\mathrm{Fe}_{2} \mathrm{O}_{3}, \mathrm{Fe}_{3} \mathrm{O}_{4}$ and $\mathrm{FeO}$}

The spectrum of wustite (FeO) [166] has a simple rock salt structure and is simulated using a crystal field of $10 \mathrm{Dq}=0.4 \mathrm{eV}$. The agreement between experiment and simulation is better if the $3 d$ spin-orbit coupling is not taken into account (green line), suggesting that the $3 \mathrm{~d}$ spin-orbit coupling is effectively quenched due to a symmetry reduction and/or translation symmetry. The theoretical spectrum should be broadened to compare better with experiment, but we prefer to show sharper theoretical curves to indicate more precisely the peak positions. Charge transfer effects significantly modify the calculation but the absence of fine structure does not allow a detailed determination of the charge transfer parameters. The calculations by Kuiper et al. for hematite $\left(\alpha-\mathrm{Fe}_{2} \mathrm{O}_{3}\right)[164,165]$ were repeated and are shown in Fig. 8(b). The calculated spectrum was simulated using a value of $10 \mathrm{Dq}=1.45$. The Slater integrals were reduced to $70 \%$ of their Hartree-Fock values to simulate charge transfer effects. Magnetite, $\mathrm{Fe}_{3} \mathrm{O}_{4}$, has a cubic inverse spinel structure that consists of three types of Fe ions: $\mathrm{Fe}^{2+}$ ions in octahedral symmetry and $\mathrm{Fe}^{3+}$ in both octahedral and tetrahedral symmetry. The absence of structure makes the detailed simulation difficult. In fact, the X-ray Magnetic Circular Dichroism spectrum contains much more structure and allows a detailed simulation [164].

Table 2 collects the main papers that contain the 2p XAS and/or $2 p$ EELS spectra of the binary oxides. A full table that includes links to the papers can be found at the [1].

\subsection{Theory D: linear dichroism and XMCD}

The X-ray absorption spectra discussed up to this point do relate to the polarization averaged XAS spectra. The X-rays from a

\section{Table 2}

The 2pXAS and 2pEELS papers on the binary iron oxides. This table is an extract from the full table that is maintained at the XASEELS database website (2010).

\begin{tabular}{|c|c|}
\hline \multicolumn{2}{|c|}{ Binary iron oxides 2p XAS and 2p EELS spectra } \\
\hline $\mathrm{FeO}$ & $\begin{array}{l}\text { [177] EELS - [60] EELS - [63] XAS - } \\
\text { [275] XAS - [166] CALC - [209] CALC - } \\
{[141] \text { XAS - [261] XAS }}\end{array}$ \\
\hline $\mathrm{Fe}_{2} \mathrm{O}_{3}$ & $\begin{array}{l}{[158] \text { EELS - [60] EELS - [165] XAS - }} \\
\text { [64] CALC - [230] XAS - [100] EELS - } \\
{[167] \text { CALC }-[217] \text { XAS }-[146] \text { XAS - }} \\
{[267] \text { EELS }-[204] \text { EELS }-[275]-[35]} \\
\text { XMCD - RIXS - [73] XAS - [136] XAS - } \\
{[279] \text { XAS - [39] XAS - [180] XAS - }} \\
{[52] \text { EELS - [142] XMCD - [263] XAS - }} \\
{[261] \text { XAS - [106] XAS - [34] RIXS - }} \\
{[273] \text { RIXS }}\end{array}$ \\
\hline $\mathrm{Fe}_{3} \mathrm{O}_{4}$ & $\begin{array}{l}\text { [60] EELS - [64] CALC - [164] XMCD - } \\
{[145] \text { XAS - [146] XAS - [85] EELS - }} \\
{[231] \text { XMCD - [237] XMCD - [9] XMCD }} \\
-[279] \text { EELS - [39] XAS - [56] XMCD - } \\
{[233] \text { RIXS - [45] XMCD - [52] XMCD - }} \\
{[219] \text { XMCD - [256] XMCD - [174] EELS }} \\
-[41] \text { XMCD - [38] EELS - [57] XMCD }\end{array}$ \\
\hline $\mathrm{Fe}_{3} \mathrm{O}_{4} / \mathrm{Pt}$ & [232] XMCD - [205] XMCD \\
\hline $\mathrm{Fe}_{3} \mathrm{O}_{4} / \mathrm{GaAs}$ & [190] XMCD \\
\hline
\end{tabular}

synchrotron source a linearly polarized, implying that system that has a different order in the propagation direction than perpendicular to it will have a polarization dependence in the XAS signal. A similar reasoning is true for an EELS spectrum. Clear examples are surface atoms, which will have a different bonding in the plane of the surface from out-of-plane. In addition, many systems contain a crystal structure that has bulk polarization dependence. Essentially any system with symmetry lower than cubic will have polarization dependence, also denoted as linear dichroism. In practice, many measurements are performed on polycrystalline/powder samples where for random orientation the polarization dependence cancels out. It should be noted however, that in X-ray and electron microscopy, local orientation of the measured area is possible also for media that are disordered on a macroscopic scale. X-rays can also be polarized circularly, using out-of-plane radiation or dedicated insertion devices. Circular polarized X-rays are used to measure X-ray Magnetic Circular Dichroism (XMCD) that is used to study magnetic systems as well as magnetized paramagnetic centers. For further details we refer to dedicated reviews on XMCD $[247,248,268,283,227]$. The XMCD sum rules are briefly discussed in Section 5.3 .

Two fundamental studies on the polarization dependence on iron oxides have been performed by Kuiper et al. [164,165]. $\alpha$ $\mathrm{Fe}_{2} \mathrm{O}_{3}$ has a magnetic phase transition at $263 \mathrm{~K}$, known as the Morin transition, where its antiferromagnetically coupled spins rotate $90^{\circ}$ with respect to the $c$-axis. This implies that the linear dichroism inverts. $\mathrm{Fe}_{3} \mathrm{O}_{4}$ has an inverted spinel structure as mentioned before, where the iron atoms are found in octahedral sites and tetrahedral sites. The octahedral site has $50 \% \mathrm{Fe}^{2+}$ and $50 \% \mathrm{Fe}^{3+}$ occupation and the tetrahedral site is $100 \% \mathrm{Fe}^{3+}$. The XMCD spectrum of $\mathrm{Fe}_{3} \mathrm{O}_{4}$ was simulated with crystal field multiplet simulations, as performed by Kuiper et al. [165]. This approach to distinguish the three different sites plus valences in spinel structures was subsequently applied to determine the relative occupation of these sites in mixed spinel systems [214].

\subsection{Iron perovskites: doping effects and $\mathrm{Fe}^{4+}$}

$\mathrm{LaFeO}_{3}$ has a perovskite structure where each iron is surrounded by six oxygen atoms in a, distorted, octahedron. The iron atoms are linked via linear chains in three directions. The 2p XAS spectrum of $\mathrm{LaFeO}_{3}$ has been measured by Abbate et al. and analyzed with a crystal field multiplet analysis [3]. The spectrum can be simulated with a crystal field value of $1.8 \mathrm{eV}$. The $\mathrm{LaFeO}_{3}$ spectrum is very similar to the $\alpha-\mathrm{Fe}_{2} \mathrm{O}_{3}$ spectrum, which also shows the relative insensitivity of a $3 \mathrm{~d}^{5}$ ground state toward its detailed surroundings.

$\mathrm{SrFeO}_{3}$ formally is an $\mathrm{Fe}^{4+}$ system. The 2p XAS spectrum, in combination with photoemission spectra, can be analyzed using a charge-transfer multiplet calculation with a charge transfer energy $\Delta$ of 0.0 . The resulting ground state that has $36 \% 3 \mathrm{~d}^{4}, 58 \% 3 \mathrm{~d}^{5} \mathrm{~L}$, and $6 \% 3 \mathrm{~d}^{6} \mathrm{~L}^{2}$ occupations [5]. This assignment is confirmed by Kang et al. [141], who conclude that $\mathrm{SrFeO}_{3}$ cannot be described as a charge ordered $3+/ 5+$ system. The $\mathrm{Fe}^{4+}$ ground state of $\mathrm{SrFeO}_{3}$ with its charge transfer energy of zero is similar to the ground state of $\mathrm{Cu}^{3+}$ oxides that also have a $\Delta$ value of approximately zero $[130,131]$.

A number of dopant series have been measured for iron perovskites, including the ( $\mathrm{La}, \mathrm{Sr}) \mathrm{FeO}_{3}$ series [3], the $\mathrm{Sr}(\mathrm{Fe}, \mathrm{Co}) \mathrm{O}_{3}$ series $[5,210]$ and the $\mathrm{Sr}(\mathrm{Fe}, \mathrm{Mn}) \mathrm{O}_{3}$ series [142]. As far as 2p XAS spectra are concerned, dopant series can be analyzed with the assumption that on the time scale of the $\mathrm{X}$-ray excitation, the local charge states are fixed. For example a $\left(\mathrm{La}_{0.5} \mathrm{Sr}_{0.5}\right) \mathrm{FeO}_{3}$ system can be assumed to contain $50 \% \mathrm{Fe}^{3+}$ and $50 \% \mathrm{Fe}^{4+}$ (Table 3 ). 
Table 3

The 2 pXAS and 2 pEELS papers on iron perovskites. This table is an extract from the full table that is maintained at the XASEELS database website (2010).

\begin{tabular}{|c|c|}
\hline \multicolumn{2}{|c|}{ Iron perovskites $2 \mathrm{p}$ XAS and $2 \mathrm{p}$ EELS spectra } \\
\hline $\mathrm{LaFeO}_{3}$ & $\begin{array}{l}\text { [3] XAS - [235] PEEM - [253] CALC - [66] } \\
\text { XMCD - [118] XAS }\end{array}$ \\
\hline $\mathrm{SrFeO}_{3}$ & $\begin{array}{l}{[141] \text { XAS }-[3] \text { XAS }-[210] \text { XMCD }-[253]} \\
\text { CALC }-[87] \text { EELS }-[95] \text { XAS }-[96] \text { XAS }\end{array}$ \\
\hline $\mathrm{Sr}(\mathrm{Ti}, \mathrm{Fe}) \mathrm{O}_{3}$ & [245] EELS \\
\hline$(\mathrm{Mg}, \mathrm{Fe})(\mathrm{Si}, \mathrm{Al}) \mathrm{O}_{3}$ & [176] EELS \\
\hline $\mathrm{BiFeO}_{3}$ & $\begin{array}{l}\text { [17] XMCD - [296] RIXS - [297] RIXS - } \\
{[195] \text { XMCD - [289] XMCD }}\end{array}$ \\
\hline $\mathrm{BiFeO}_{3}(\mathrm{Sr})$ & [241] XMCD \\
\hline $\mathrm{Nd}(\mathrm{Fe}, \mathrm{Ni}) \mathrm{O}_{3}$ & [16] XAS \\
\hline$(\mathrm{Ba}, \mathrm{Sr})(\mathrm{Fe}, \mathrm{Zn}) \mathrm{O}_{3}$ & [87]- EELS \\
\hline $\mathrm{Sr}_{2} \mathrm{FeMoO}_{6}$ & $\begin{array}{l}{[22] \text { XMCD - [147] XMCD - [140] XMCD - }} \\
{[162] \text { XMCD }}\end{array}$ \\
\hline $\mathrm{Sr}_{3} \mathrm{Fe}_{2} \mathrm{O}_{7}$ & [4] XAS \\
\hline
\end{tabular}

Table 4

The 2pXAS and 2pEELS papers on iron spinel ferrites. This table is an extract from the full table that is maintained at the XASEELS database website (2010).

\begin{tabular}{ll}
\hline Iron spinel ferrites 2p XAS and 2p EELS spectra \\
\hline $\mathrm{MnFe}_{2} \mathrm{O}_{4}$ & {$[141]$ XMCD - [197] XMCD } \\
$\mathrm{CoFe}_{2} \mathrm{O}_{4}$ & {$[134]$ XMCD - [214] XMCD - [295] XMCD } \\
$\mathrm{CoFe}_{2} \mathrm{O}_{4} / \mathrm{BiFeO}_{3}$ & {$[291]$ PEEM } \\
$\mathrm{NiFe}_{2} \mathrm{O}_{4}$ & {$[214]$ XMCD - [254] EELS } \\
$\mathrm{ZnFe}_{2} \mathrm{O}_{4}$ & {$[266]$ EELS - [222] XAS } \\
$\mathrm{MgFe}_{2} \mathrm{O}_{4}$ & {$[214]$ XMCD } \\
$(\mathrm{Mg}, \mathrm{Fe})_{2} \mathrm{SiO} 4$ & {$[92]$ EELS } \\
$\mathrm{FeAl}_{2} \mathrm{O}_{4}$ & {$[157] \mathrm{EELS} \mathrm{-} \mathrm{[266]} \mathrm{EELS} \mathrm{-} \mathrm{[72]} \mathrm{EELS}$} \\
$(\mathrm{Ni}, \mathrm{Co}, \mathrm{Zn}) \mathrm{Fe}_{2} \mathrm{O}_{4}$ & {$[222] \mathrm{XAS}-[122]$ XMCD - [214] XMCD } \\
$(\mathrm{Mn}, \mathrm{Zn}, \mathrm{Fe})_{3} \mathrm{O}_{4}$ & {$[23]$ XMCD } \\
$(\mathrm{Fe}, \mathrm{Cr}, \mathrm{Al}, \mathrm{Mg}) \mathrm{O}_{4}$ & {$[249]$ EELS }
\end{tabular}

\subsection{Iron spinels: site determination from $X M C D$}

Spinel ferrites consist of a group of oxides that crystallize in the spinel crystal structure. The general chemical formula is $\mathrm{MFe}_{2} \mathrm{O}_{4}$, where $\mathrm{M}$ is another metal atom, including $\mathrm{CoFe}_{2} \mathrm{O}_{4}, \mathrm{MnFe}_{2} \mathrm{O}_{4}$, $\mathrm{NiFe}_{2} \mathrm{O}_{4}, \mathrm{ZnFe}_{2} \mathrm{O}_{4}$ and $\mathrm{MgFe}_{2} \mathrm{O}_{4}$. For most samples, both natural and synthetic, the spinel ferrite will have a non-stoichiometric amount of Fe and M. The occupation of the tetrahedral and octahedral sites and the variation of divalent and trivalent ions for Fe and $\mathrm{M}$ are found to vary from system to system. In addition spinel ferrites with two or more additional atoms, for example $(\mathrm{Co}, \mathrm{Ni}, \mathrm{Fe}) \mathrm{O}_{4}$, can be found.

The line shape of the Fe 2p XAS spectrum of $\mathrm{MnFe}_{2} \mathrm{O}_{4}$ is similar to those of both $\alpha-\mathrm{Fe}_{2} \mathrm{O}_{3}$ and $\gamma-\mathrm{Fe}_{2} \mathrm{O}_{3}$ indicating that the valence states of $\mathrm{Fe}$ ions in $\mathrm{MnFe}_{2} \mathrm{O}_{4}$ are mainly trivalent. Spectral details indicate that $\mathrm{Fe}$ ions in $\mathrm{MnFe}_{2} \mathrm{O}_{4}$ occupy both $\mathrm{O}_{\mathrm{h}}$ and $\mathrm{T}_{\mathrm{d}}$ sites. Multiplet calculations yield a mixture of $90 \% \mathrm{Fe}_{\mathrm{B}}{ }^{3+}\left(\mathrm{O}_{\mathrm{h}}\right)$ and $10 \%$ $\mathrm{Fe}^{3+}\left(\mathrm{T}_{\mathrm{d}}\right)$ [141]. Pattrick and coworkers [214] analyzed a series of mixed spinel ferrite systems with 2p XAS and XMCD. By comparison with multiplet spectra, the site occupancies of the cations have been determined. It turns out that the different mixed $(\mathrm{Co}, \mathrm{Ni}, \mathrm{Zn}$, $\mathrm{Mg}$ ) ferrite spinels show considerable variation in site occupancies. Incomplete site speciation is found and the preference of Co, $\mathrm{Ni}$ and $\mathrm{Mg}$ for the octahedral site and $\mathrm{Zn}$ for the tetrahedral site is confirmed. An overview of the $2 p$ XAS and XMCD spectra of spinel ferrites have been given by Pearce et al. [215] (Table 4).

\subsection{Other iron oxides}

Ilmenite $\mathrm{FeTiO}_{3}$ is often studied with respect to its $\mathrm{Fe}^{2+}$ : $\mathrm{Ti}^{4+}$ ions and their related charge transfer channel to $\mathrm{Fe}^{3+}: \mathrm{Ti}^{3+}$. The experimental 2p XAS spectra suggest a mixed valence $\mathrm{Fe}^{2+}: \mathrm{Fe}^{3+}$ oxide $[6,80]$ : In contrast, recent 2 p EELS spectra show a pure $\mathrm{Fe}^{2+}$ ground state, as confirmed by multiplet calculations [224].
$\mathrm{GaFeO}_{3}$ : The orbital and bonding anisotropies in $\mathrm{GaFeO}_{3}$ are induced by the lattice distortions with off-center site displacements. This yields a system with a large magnetocrystalline energy and magnetoelasticity, in which ferrimagnetism and piezoelectricity coexist. Iron in $\mathrm{GaFeO}_{3}$ is $\mathrm{Fe}^{3+}$ with a sextet ground state without any orbital moment. The $\mathrm{Fe}-\mathrm{O}$ hybridization is highly anisotropic, yielding a bonding induced orbital moment. The $2 \mathrm{p}$ XAS and XMCD spectrum confirm the $\mathrm{Fe}^{3+}$ state with a large orbital moment, as obtained from the sum rule [148]. The large off-center site symmetry of the iron atoms is used in resonant diffraction experiments at the iron $\mathrm{L}_{2,3}$ edge [243]. The coupling of electric dipole (E1) with magnetic dipole (M1) transitions can be studied with resonant diffraction.

Iron garnets: The $2 \mathrm{p}$ X-ray absorption spectrum and its XMCD of gadolinium iron garnet, $\mathrm{Fe}_{5} \mathrm{Gd}_{3} \mathrm{O}_{12}$, has been measured by Rudolf et al. [226]. Garnets contain two sub-lattices of ferric ions, anti-ferromagnetically coupled by super-exchange through oxygen atoms, which respectively contain three $\mathrm{Fe}^{3+}$ per formula unit on tetrahedral sites and two $\mathrm{Fe}^{2+}$ per formula unit on octahedral sites. Recently this system has been used for ferromagnetic resonance spectroscopy at the iron L edge [26]. Instead of a rare earth, the garnet structure also appears for iron silicates such as the mineral skiagite $\mathrm{Fe}_{5} \mathrm{Si}_{3} \mathrm{O}_{12}$ [266]. The $\mathrm{Fe}^{2+}$ site can be replaced by $\mathrm{Ca}^{2+}$, yielding $\mathrm{Ca}_{3} \mathrm{Fe}_{2} \mathrm{Si}_{3} \mathrm{O}_{12}$ and the $\mathrm{Fe}^{3+}$ site can be replaced by $\mathrm{Al}^{3+}$, yielding $\mathrm{Fe}_{3} \mathrm{Al}_{2} \mathrm{Si}_{3} \mathrm{O}_{12}$. The $2 \mathrm{p}$ EELS spectra of these systems are given by van Aken and Liebscher [266].

Iron phosphates: Recently, two different $\mathrm{FePO}_{4}$ crystal structures have been measured. As was confirmed in both Studies with multiplet calculations, tetrahedral $\mathrm{Fe}^{3+}$ was found for a rodolicoite crystal [72], while octahedral $\mathrm{Fe}^{3+}$ was found for a heterosite $\mathrm{FePO}_{4}$ crystal [12]. The crystal field splitting found were respectively -0.9 for rodolicoite, while a value of $+1.45 \mathrm{eV}$ was found for heterosite. The negative number for rodolicoite indicates the $\mathrm{T}_{\mathrm{d}}$ symmetry. The study from Augustsson compares $\mathrm{FePO}_{4}$ with $\mathrm{Li}_{x} \mathrm{FePO}_{4}$ [12]. $\mathrm{Li}_{x} \mathrm{FePO}_{4}$ is one of the most promising candidates to replace cobalt oxides as cathode materials in lithium-ion batteries. The addition of Li lowers the iron valence from $3+$ to $2+$ and reduces the cubic crystal field from 1.45 in $\mathrm{FePO}_{4}$ to 0.5 in $\mathrm{LiFePO}_{4}$.

Iron carbonate: $\mathrm{FeCO}_{3}$, also known as siderite, contains $\mathrm{Fe}^{2+}$ ions in a $\mathrm{C}_{3 \mathrm{v}}$ distorted octahedral symmetry. The $2 \mathrm{p}$ XAS spectrum can be simulated with multiplet calculations [40], where the peak at $719 \mathrm{eV}$ suggest that the $3 \mathrm{~d}$ spin-orbit coupling is quenched [72]. In addition to the $2 \mathrm{p}$ XAS spectrum, also the $2 \mathrm{p} 3 \mathrm{~d}$ RIXS spectra can be reproduced from multiplet calculations $[40,71]$.

Potassium iron jarosite $\left[\mathrm{KFe}_{3}\left(\mathrm{SO}_{4}\right)_{2}(\mathrm{OH})_{6}\right]$ [78]: The jarosite group of minerals has received much attention for being close to ideal realizations of the kagome anti-ferromagnet. The kagome topology, which is named after a Japanese basket weaving pattern, frustrates the anti-ferromagnetic Néel ordering. Due to the resulting "under-constraint" neither in the quantum case of $S=1 / 2$ nor in the classical limit is the kagome anti-ferromagnet expected to show a symmetry-breaking transition, even at $T=0 \mathrm{~K}$. Physical realizations of this system are highly valued because they allow for the investigation of the Mott insulating phase in the absence of Néel-type magnetic order.

Fe:ZnO: Kataoka et al. investigated $\mathrm{Fe}$ in $\mathrm{ZnO}$ as an example of a magnetic ion doped into a semiconductor host [143]. They doped $10 \% \mathrm{Fe}$ in $\mathrm{ZnO}$ powder. XPS showed that there is a $\mathrm{Fe}^{3+}-\mathrm{Fe}^{2+}$ mixed valent state of the Fe ions in the $\mathrm{ZnO}$ :Fe. However, if Fe would simply substitute $\mathrm{Zn}, \mathrm{Fe}^{2+}$ would be expected. The presence of $\mathrm{Fe}^{3+}$ may be due to surface $\mathrm{Zn}$ vacancies or excess oxygens of the nanoparticles. From XMCD of $\mathrm{ZnO}$ :Fe it is seen that the spectrum is different from the metal, indicating that the magnetism in this sample is not due to segregation of metallic Fe clusters but due to the ionic Fe atoms with localized 3d electrons. Comparing the XMCD with $\gamma$ $\mathrm{Fe}_{2} \mathrm{O}_{3}$ and $\mathrm{Fe}_{3} \mathrm{O}_{4}$ it was noticed that the $\mathrm{Fe}^{3+}$ ions are in both $\mathrm{T}_{d}$ 
Table 5

The 2pXAS and 2pEELS papers on iron garnets, silicates and other iron oxides. This table is an extract from the full table that is maintained at the XASEELS database website (2010).

\begin{tabular}{|c|c|}
\hline \multicolumn{2}{|c|}{ Other iron oxides 2p XAS and 2p EELS spectra } \\
\hline $\mathrm{FeOOH}$ & [52] EELS \\
\hline $\mathrm{Fe}_{2} \mathrm{O}_{3}\left(\mathrm{H}_{2} \mathrm{O}\right)$ & [110] EELS - [115] XMCD \\
\hline $\mathrm{FeTiO}_{3}$ & $\begin{array}{l}\text { [80] PEEM - [100] EELS - [6] XAS - [224] EELS } \\
-[93] \text { XMCD - [252] EELS }\end{array}$ \\
\hline$(\mathrm{Fe}, \mathrm{Ti}) \mathrm{Ox}$ & [216] XMCD - [189] XAS \\
\hline $\mathrm{GaFeO}_{3}$ & [148] XMCD - [243] XAS \\
\hline $\mathrm{CaBaFe}_{4} \mathrm{O}_{7}$ & {$[126]$ XAS } \\
\hline $\mathrm{Ca}(\mathrm{Al}, \mathrm{Fe}) \mathrm{O}_{2.5}$ & [108] EELS - [109] EELS - [264] \\
\hline $\mathrm{Fe}_{5} \mathrm{Gd}_{3} \mathrm{O}_{12}$ & [226] XMCD - [26] XAS \\
\hline $\mathrm{Fe}_{5} \mathrm{Si}_{3} \mathrm{O}_{12}$ & [266] EELS \\
\hline $\mathrm{BaFeSi}_{4} \mathrm{O}_{10}$ & {$[270]$ XMCD - [234] XMCD } \\
\hline $\mathrm{FePO}_{4}$ & $\begin{array}{l}\text { [12] RIXS - [173] EELS - [72] XAS - [286] XAS - } \\
\text { [189] XAS }\end{array}$ \\
\hline $\mathrm{LiFePO}_{4}$ & [12] RIXS - [173] EELS - [286] XAS - [189] XAS \\
\hline $\mathrm{Li}(\mathrm{Mn}, \mathrm{Fe}) \mathrm{PO}_{4}$ & [127] RIXS \\
\hline $\mathrm{Fe}_{3}\left(\mathrm{PO}_{4}\right)_{2}$ & [203] XAS \\
\hline $\mathrm{FeCO}_{3}$ & [40] RIXS - [274] XAS - [39] XAS - [52] EELS \\
\hline $\mathrm{KFe}_{3}\left(\mathrm{SO}_{4}\right)_{2}(\mathrm{OH})_{6}$ & [78] XMCD \\
\hline $\mathrm{KAlSi}_{3} \mathrm{O}_{8}(\mathrm{Fe})$ & [223] XAS \\
\hline $\mathrm{Fe}_{2} \mathrm{SiO}_{4}$ & [100] EELS - [266] EELS - [72] XAS \\
\hline$(\mathrm{Fe}, \mathrm{Ni}) \mathrm{O}$ & [49] XAS \\
\hline (Fe,Mg)O & [107] EELS \\
\hline$(\mathrm{Fe}, \mathrm{Na}, \mathrm{Si}) \mathrm{O}$ & [86] XAS \\
\hline Fe minerals & [99] - [100] - [265] EELS - [266] EELS - [290] \\
\hline & EELS - [108] EELS - [213] EELS - [67] EELS \\
\hline
\end{tabular}

and $\mathrm{O}_{\mathrm{h}}$ holes and that the $\mathrm{Fe}^{2+}$ ion contribution to the magnetism is small.

Fe/NiO films: Alvarenga et al. studied a thin film of Fe/NiO [7]. This is mainly interesting in view of the exchange bias coupling. In principle $\mathrm{NiO}$ is antiferromagnetic, while the iron is ferromagnetic. Different Fe thicknesses on NiO were investigated with a probing depth of $\sim 50-200 \AA$. The XMCD increases from $\sim 200 \AA$ to $175 \AA$ and then stays constant till a probing depth of approximately $100 \AA$. Then the XMCD decreases again untill $50 \AA$ (when the interface with $\mathrm{NiO}$ is also probed). Formation of $\mathrm{FeO}$ at the $\mathrm{Fe} / \mathrm{NiO}$ interface might be the reason for the decrease of XMCD signal. Chen et al. investigated a $\mathrm{Fe}_{1-x} \mathrm{Ni}_{x} \mathrm{O}_{y}$ alloy thin film with changing the Fe:Ni ratio [49]. The XAS of these $\mathrm{Fe}-\mathrm{Ni}-\mathrm{O}$ alloys are compared with XAS of $\mathrm{Fe}_{3} \mathrm{O}_{4}$ and $\mathrm{Fe}_{2} \mathrm{O}_{3}$ thin films. From $\mathrm{Fe}_{0.85} \mathrm{Ni}_{0.15} \mathrm{O}_{y}$ to $\mathrm{Fe}_{0.5} \mathrm{Ni}_{0.5} \mathrm{Oy}$ and further, the spectral shape approaches the one of $\mathrm{Fe}_{2} \mathrm{O}_{3}$. With increasing $x$-value (=decreasing amount of iron) the amount of octahedral Fe increases, while for $\mathrm{Fe}_{0.85} \mathrm{Ni}_{0.15} \mathrm{O}_{\mathrm{y}}$ some peaks corresponding to $\mathrm{Fe}^{2+}$ and $\mathrm{Fe}^{3+}$ can be found. At $x=0.5 \mathrm{Ni}^{2+}$ seems to have taken over the $\mathrm{Fe}^{2+}$ sites (Table 5).

\subsection{Application II: iron complexes and nanostructures in catalysis}

Heijboer et al. measured the 2p XAS spectra of Fe complexes in ZSM5 zeolites, where in contrast to most other 2p XAS and EELS experiments, these experiments are performed under a few mbar pressure $[119,120]$. Zeolites are Al-doped $\mathrm{SiO}_{2}$ structures with a two-dimensional pore structure. Fe/ZSM5 is able to oxidize all hydrocarbons using so-called $\alpha$-oxygen active sites. From comparison with bulk iron-oxides and from charge transfer multiplet calculations, Heijboer et al. show that the spectra of FeZSM5 under oxygen respectively hydrogen are related to respectively $\mathrm{Fe}^{3+}$ and $\mathrm{Fe}^{2+}$. The $\mathrm{Fe}^{3+}$ site is octahedral with a crystal field value $10 \mathrm{Dq}=1.0 \mathrm{eV}$. This value is lower than in the case of $\mathrm{Fe}_{2} \mathrm{O}_{3}(1.5 \mathrm{eV})$ indicating weaker iron-oxygen bonds in the zeolite. The $\mathrm{Fe}^{2+}$ site is tetrahedral and is simulated with a crystal field of $10 \mathrm{Dq}=-1 \mathrm{eV}$. This is similar to the bulk oxide $\mathrm{FeAl}_{2} \mathrm{O}_{4}$.

One can combine 2p XAS experiments with a Scanning Transmission X-ray Microscope (STXM) to yield a resolution of $\sim 20 \mathrm{~nm}$ for the iron 2p XAS spectra. This yields the option to measure iron L edges with $20 \mathrm{~nm}$ spatial resolution. Using a nanoreactor with $10 \mathrm{~nm}$ thick windows and $50 \mu \mathrm{m}$ path length experiments up to 2 bar and $750 \mathrm{~K}$ are possible [76,77]. The range of applications of this technique focuses on the nanoscale imaging of in situ processes in catalysis and materials science [75,221].

\subsection{Application III: mineralogy}

$2 \mathrm{p}$ XAS and $2 \mathrm{p}$ EELS is an important tool to derive important information on the speciation of minerals. This includes the determination of the spin-state and crystal field strength, derived from spectral interpretation and fitting, including the determination of the $\mathrm{L}_{3}: \mathrm{L}_{2}$ intensity (branching) ratio and other peak intensity ratios. An important tool is the combination of 2 pEELS or 2 pXAS with microscopy. Spectromicroscopic studies reach $20 \mathrm{~nm}$ resolution for 2 pXAS and $0.2 \mathrm{~nm}$ resolution for 2 pEELS. An important parameter is the ratio of the $\mathrm{Fe}^{2+} / \mathrm{Fe}^{3+}$ ions in a mineral. This ratio is usually given as the fraction $\mathrm{Fe}^{3+}, \mathrm{Fe}^{3+} / \Sigma \mathrm{Fe}$. Systematic studies of the Fe $2 \mathrm{p}$ EELS spectra of a large series of minerals yielded a reliable method to determine this ratio, based on the determination of the ratio of the $\mathrm{Fe}^{3+}$ and $\mathrm{Fe}^{2+}$ peaks in the $\mathrm{L}_{3}$ edge [266].

A major advantage of using EELS is that one has better spatial resolution than with X-ray microscopy (STXM), so one can obtain information about iron at different places in a system. Fig. 9 shows the iron 2p EELS spectrum of the small crystallites on the edge of a zeolite crystal. Analysis of the 2 p EELS spectral shapes confirmed that the nature of these nanoparticles as $\mathrm{Fe}_{2} \mathrm{O}_{3}$ [121]. In another study, Chen et al. apply $2 p$ EELS spectromicroscopy to field- and template-free hydrothermal synthesized iron oxide nanoparticles (NP), short nanowires (SNW) and big plates [52].

\section{Iron metal alloys and covalent iron materials}

Iron smetal, iron sulfides and other covalent iron materials have a 2p X-ray absorption spectrum with little structure. The covalent interactions create a ground state that cannot be described well with one or two configurations. The consequence of the broad, often structure-less, spectra is that it is difficult to derive much information from spectral analysis. In many cases, the analysis has to rely on more qualitative features, such as peak position, branching ratio and integrated intensity. We note here that the $2 \mathrm{p}$ XAS experiment is only the initial excitation of the system and one can use this excitation in a range of information-rich spectra and features. This includes resonant (inelastic) X-ray scattering and diffraction for which the spectroscopy involving the same atoms and actually the same excitations becomes very rich and full of detailed fine structure and long range order dependencies not visible in the XAS spectra [48]. We start with an analysis of metal sulfides, which occasionally have some fine structure.

\subsection{Application IV: the branching ratio}

The branching ratio is the ratio between the integrated intensities of the $\mathrm{L}_{3}$ and the $\mathrm{L}_{2}$ edge, formally defined as $I_{\mathrm{L} 3} /\left(I_{\mathrm{L} 3}+I_{\mathrm{L} 2}\right)$. If only the $2 \mathrm{p}$ spin-orbit coupling is considered the intensity of the $\mathrm{L}_{3}$ and $\mathrm{L}_{2}$ edges are given by the degeneracy of their $J$-value, respectively $4\left(L_{3}\right)$ and $\left(L_{2}\right)$. The branching ratio then is $2 / 3$.This statistical ratio is modified by the $3 \mathrm{~d}$ spin-orbit coupling and especially by the $2 \mathrm{p} 3 \mathrm{~d}$ multiplet effects. One can relate the branching ratio to the spin nature of the ground state, where high-spin states have a higher branching ratio then low-spin states [258]. In case of $4 d$ elements, the $2 \mathrm{p}$ spin-orbit coupling is much larger and the $2 \mathrm{p} 4 \mathrm{~d}$ multiplets can be neglected. Only the $4 \mathrm{~d}$ spin-orbit coupling then affects the branching ratio [69,70]. 

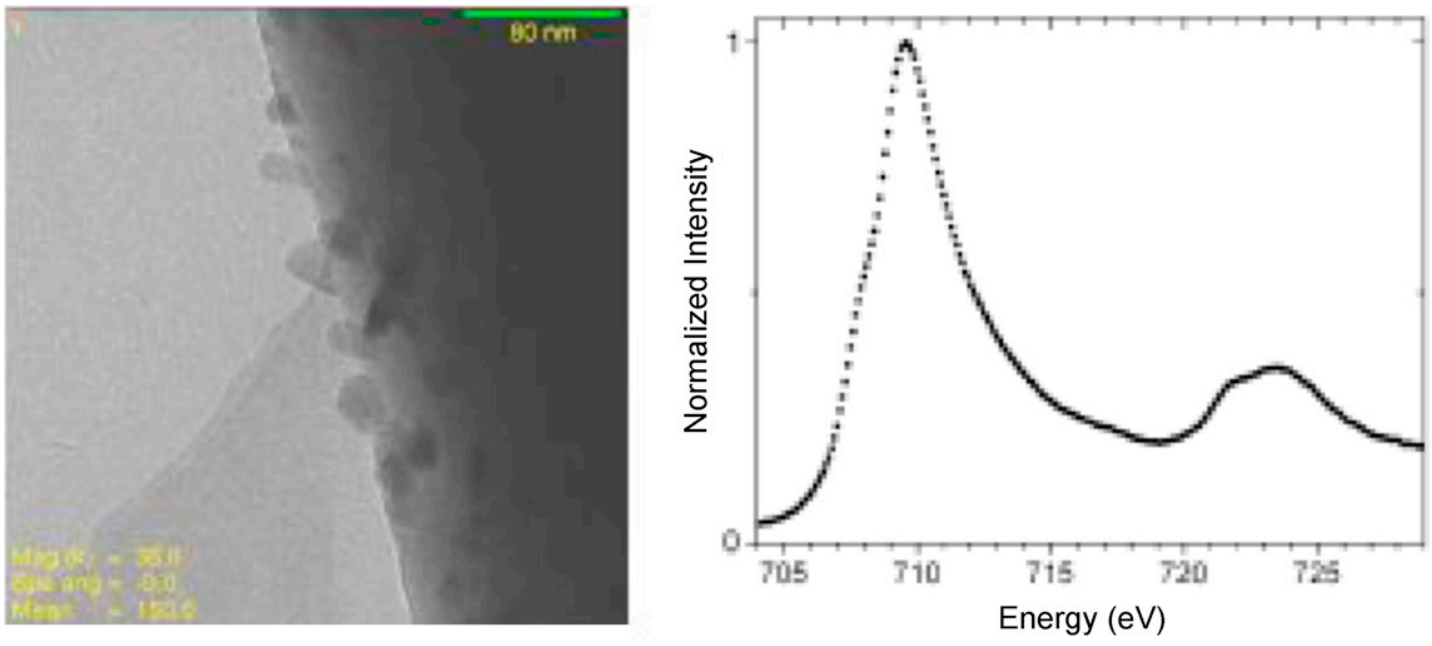

Fig. 9. (Left) 2p EELS spectrum of the $\sim 20 \mathrm{~nm}$ sized nanoparticles on the outside of a large zeolite single crystal [121].

\subsection{Iron sulfides}

The $2 \mathrm{p}$ XAS spectrum of $\mathrm{Fe}_{7} \mathrm{~S}_{8}$ shows a detailed fine structure that is even clearer in the associated XMCD spectrum. Fig. 10 shows the XAS and XMCD spectra that reveal the $\mathrm{Fe}^{2+}$ nature of iron in this system and the spectra can be simulated with charge transfer multiplet calculations [183]. The charge transfer parameters indicate a small crystal field strength $(0.5 \mathrm{eV})$, a charge transfer energy $\Delta$ of $3.0 \mathrm{eV}$ and a strong hopping (covalence) of $3.0 \mathrm{eV}$ for the e electrons, with $\mathrm{Tt}_{2 \mathrm{~g}}=1 / 2 \mathrm{Te}$. The charge transfer multiplet calculation accurately reproduces the experimental spectrum.

The spectra for FeS show some variation between different experiments. One would expect similar spectra for $\mathrm{FeS}$ and $\mathrm{Fe}_{7} \mathrm{~S}_{8}$. The published FeS spectra have however a second peak at the position of the main peak of $\mathrm{Fe}^{3+}$ systems $[215,275]$, where the intensity of this peak varies from one spectrum to the next. This could suggest partial oxidation of the $\mathrm{FeS}$ system to $\mathrm{Fe}^{3+}$ ions, where we note that the detailed STEM-EELS experiments on $\mathrm{Fe}_{3} \mathrm{~S}_{4}$ show a $\mathrm{Fe}_{3} \mathrm{~S}_{4}$ core covered with a $\mathrm{Fe}_{2} \mathrm{O}_{3}$ shell [184]. Another FeS spectrum shows only a single peak [42], but the lower experimental resolution obscures the potential fine details in the peak structure. The $\mathrm{Fe}^{3+}$ sulfides, including $\mathrm{CuFeS}_{2}$ and $\mathrm{KFeS}_{2}$, show essentially a nonstructured single peak at the $\mathrm{L}_{3}$ edge, quite different from the $\mathrm{Fe}^{3+}$ oxide systems.

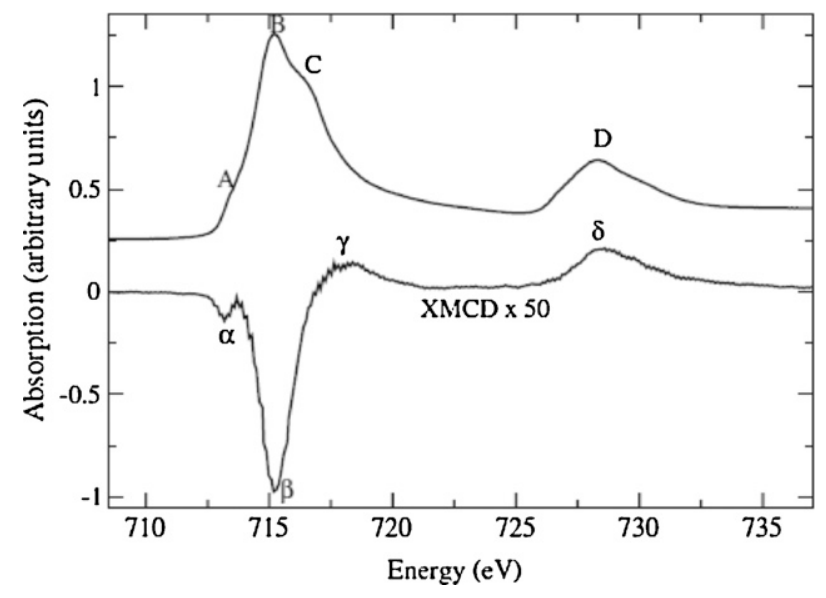

Fig. 10. 2p XAS and XMCD spectra of $\mathrm{Fe}_{7} \mathrm{~S}_{8}$ at $300 \mathrm{~K}$ and a magnetic field of $\pm 1 \mathrm{~T}$. Spectrum is taken from Letard [185].
The iron 2pXAS spectrum of $10 \%$ Fe in $\mathrm{ZnS}$ has a clear multiplet structure as can be seen in Fig. 11 [220]. The spectrum is equivalent to the $2 \mathrm{p}$ EELS spectrum of $\mathrm{FeAl}_{2} \mathrm{O}_{4}$, which was analyzed in tetrahedral symmetry with a $10 \mathrm{Dq}$ value of $-0.7 \mathrm{eV}$ [72]. The spectra of iron impurities in $\mathrm{ZnS}$ have also been calculated, reaching a similar ground state with a crystal field strength of $-0.5 \mathrm{eV}$ [36] (Table 6).

\subsection{Application V: Fe pnictide superconductors}

A new class of superconductors has recently been found, based on mixed FeAs layers with oxide layers. The iron 2p XAS spectrum has been measured for the LaFeAsO1-xFx system. The spectral shape shows the absence of well resolved features, complicating a detailed spectral analysis. Charge transfer multiplet calculations reproduce the spectral shape [159], but in our opinion the lack of detailed structure make the iron L edges not the most ideal tool to study such covalent compounds. Similar spectra are measured for the systems where La is replaced with Cd, Sm or Gd [160] and by systems with similar FeAs surroundings such as $\mathrm{CaAs}_{2} \mathrm{Fe}_{2}$ [169].

\subsection{Iron metal and intermetallic alloys: $X M C D$ and sum rules}

The iron metal spectrum essentially shows a single asymmetric structure at the $\mathrm{L}_{3}$ edge and also at the $\mathrm{L}_{2}$ edge [88]. The XMCD

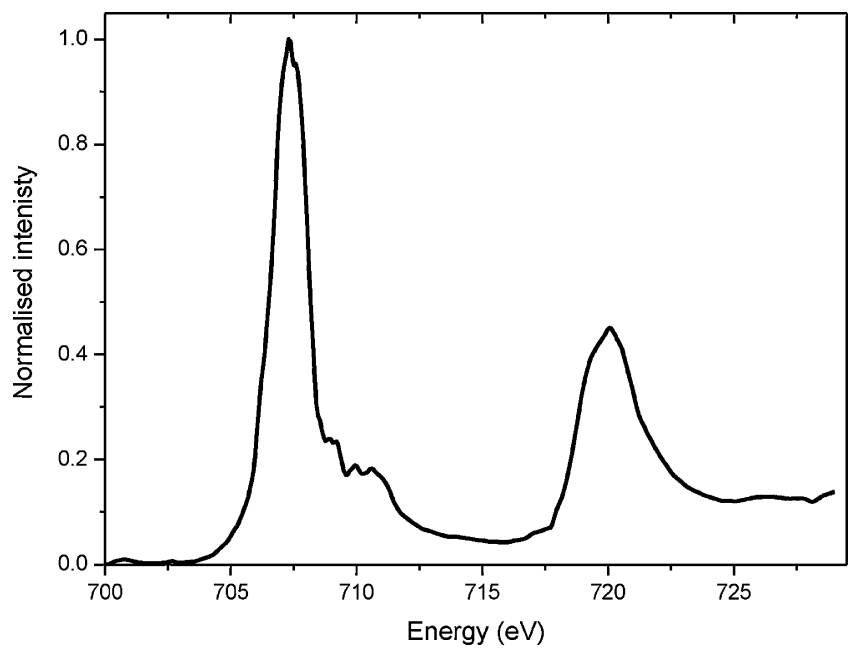

Fig. 11. $2 \mathrm{p} X A \mathrm{X}$ of $\mathrm{Fe}_{0,1} \mathrm{Zn}_{0,9} \mathrm{~S}$. Digitized from Perez-Dieste [220]. 
Table 6

The 2pXAS and 2pEELS papers on iron sulfides and other covalent iron systems. This table is an extract from the full table that is maintained at the XASEELS database website (2010).

\begin{tabular}{|c|c|}
\hline $\mathrm{FeS}$ & $\begin{array}{l}{[275] \text { XAS - [172] XAS - [42] EELS - [202] XAS - [215] }} \\
\text { XAS }\end{array}$ \\
\hline $\mathrm{FeS}_{2}$ & $\begin{array}{l}\text { [206] XAS - [46] XAS - [101] EELS - [42] EELS - [215] } \\
\text { XAS - [111] XAS }\end{array}$ \\
\hline $\mathrm{Fe}_{3} \mathrm{~S}_{4}$ & [184] XMCD - [42] EELS - [47] XMCD \\
\hline $\mathrm{Fe}_{7} \mathrm{~S}_{8}$ & [183] XMCD \\
\hline $\mathrm{KFeS}_{2}$ & [11] XAS - [215] XAS \\
\hline $\mathrm{CuFeS}_{2}$ & [262] XAS - [215] XAS - [111] XAS \\
\hline $\mathrm{Na}_{5} \mathrm{FeS}_{4}$ & [11] XAS \\
\hline FeAsS & [202] XAS \\
\hline$(\mathrm{Fe}, \mathrm{Cu}) \mathrm{Cr}_{2} \mathrm{~S}_{4}$ & [79] XMCD - [116] XMCD - [255] XMCD \\
\hline$(\mathrm{Fe}, \mathrm{Zn}) \mathrm{S}$ & [220] XAS - [36] CALC \\
\hline$(\mathrm{Fe}, \mathrm{Se})$ & [171] XAS \\
\hline $\mathrm{Fe}(\mathrm{Se}, \mathrm{Te})_{2}$ & [46] XAS - [170] - [129] EELS - [53] RIXS \\
\hline$(\mathrm{Fe}, \mathrm{N})$ & [251] XMCD - [280] XMCD \\
\hline $\mathrm{NdFe}_{2} \mathrm{~B}_{14}$ & [135] XMCD \\
\hline LaFeAsO & [160] XAS - [25] XAS - [191] XAS \\
\hline $\operatorname{LaFeAs}(\mathrm{O}, \mathrm{F})$ & [159] XAS \\
\hline $\mathrm{CeFeAs}(\mathrm{O}, \mathrm{F})$ & [27] RIXS \\
\hline PrFeAsO & [91] RIXS \\
\hline $\mathrm{La}(\mathrm{Fe}, \mathrm{Co}) \mathrm{AsO}$ & [25] XAS \\
\hline$(\mathrm{Ba}, \mathrm{K}) \mathrm{As}_{2} \mathrm{Fe}_{2}$ & [153] RPES \\
\hline $\mathrm{CaAs}_{2} \mathrm{Fe}_{2}$ & [169] RIXS \\
\hline $\mathrm{BaAs}_{2} \mathrm{Fe}_{2}$ & [198] RIXS \\
\hline $\mathrm{Fe}_{78} \mathrm{~B}_{22}(\mathrm{Y})$ & [188] XAS \\
\hline
\end{tabular}

spectrum, i.e. the difference in absorption between left- and rightcircularly polarized X-rays, has been measured in transmission mode and show also two asymmetric peaks with opposite sign for the $\mathrm{L}_{3}$ and $\mathrm{L}_{2}$ edge [50]. The L edge XMCD spectra can be analyzed with sum rules that provide, within certain approximations, the orbital and spin moments $[43,259]$. The integrated XMCD signal is proportional to the orbital moment and the weighted difference between the XMCD signal of the $\mathrm{L}_{3}$ and the $\mathrm{L}_{2}$ edge is proportional to the spin moment. The spin sum rule is not exactly correct due to the combined effects of multiplets and spin-orbit coupling; see for example a recent overview of the limitations of the sum rule [221]. After applying the XMCD sum rules to the iron spectrum, the spin moment $\left(\mathrm{m}_{\text {spin }}\right)$ and the orbital moment $\left(\mathrm{m}_{\mathrm{orb}}\right)$ can be derived and the values found were $\mathrm{m}_{\text {spin }}=1.98$ and $\mathrm{morb}=0.085$ [50]. Recent transmission XMCD spectra on iron metal yield slightly different values $\mathrm{m}_{\text {spin }}=1.60$ and $\mathrm{m}_{\text {orb }}=0.088$ [113]. The $\mathrm{Fe}_{(1-x)} \mathrm{V}_{x}$ alloys show a decrease of the spin and orbital moment, in line with other experiments [113]. Many more $\mathrm{Fe} \mathrm{L}_{2,3}$ XMCD experiments have been performed on Fe films, interfaces, and nanoparticles. We refer to the XASEELS website for an overview (Table 6a).

The use of circularly polarized X-rays to measure XMCD spectra is a well-established technique. Recently it has been shown that one can also use with an electron microscope. This technique, energy-loss magnetic chiral dichroism (EMCD), makes use of small differences in the double-differential scattering cross section of the electrons in the diffraction plane of an electron microscope [228]. Recently EMCD experiments on a Fe/Au multilayer system have been measured with $2 \mathrm{~nm}$ resolution [229].

\section{Coordination complexes and iron proteins}

Coordination complexes differ from bulk solids in the sense that they contain an isolated metal ion, or a small cluster, surrounded by organic and/or inorganic ligands. As a rule, coordination complexes occur in a wider range of symmetries, for example in square planar symmetry in flat coordination compounds. Square planar symmetries allow additional ground state symmetries, such as intermediate spin ground states. We first discuss the coordination
Table 6a

The 2pXAS and 2pEELS papers on iron metal and alloys. (a,b) indicates mixtures $\mathrm{Fe} / \mathrm{Pd}$ indicates iron on $\mathrm{Pd},[\mathrm{Fe}]$ indicates nanoparticles, $\mathrm{Fe}\left\langle\mathrm{SiO}_{2}\right\rangle$ indicated iron ions in $\mathrm{SiO}_{2}$. This table is an extract from the full table that is maintained at the XASEELS database website (2010).

\begin{tabular}{|c|c|}
\hline \multicolumn{2}{|c|}{ Metal adsorbates/interfaces and alloys 2p XAS and 2p EELS spectra } \\
\hline $\mathrm{Fe}$ & $\begin{array}{l}{[83] \text { XAS - [150] XAS - [177] EELS - [88] EELS - [149] }} \\
\text { CALC - [50] XMCD - [154] XMCD - [168] XAS - [33] } \\
\text { XMCD - [95] XAS }\end{array}$ \\
\hline $\mathrm{Fe} / \mathrm{Pd}$ & [65] XMCD - [294] XMCD \\
\hline $\mathrm{Fe} / \mathrm{Cu}$ & {$[156] \mathrm{XMCD}$} \\
\hline $\mathrm{Mn} / \mathrm{Fe}$ & [8] XMCD \\
\hline $\mathrm{Fe} / \mathrm{ZnO}$ & [143] XMCD \\
\hline $\mathrm{Fe} / \mathrm{NiO}$ & [7] XMCD \\
\hline $\mathrm{Fe} / \mathrm{InAs}$ & [257] XMCD \\
\hline $\mathrm{Fe} / \mathrm{GaAs}$ & [285] XMCD - [55] XMCD - [211] XMCD \\
\hline $\mathrm{Fe} / \mathrm{ZnSe}$ & {$[194]$ XMCD } \\
\hline$[\mathrm{Fe}] / \mathrm{Co} / \mathrm{W}$ & [151] XMCD \\
\hline$[\mathrm{Fe}] / \mathrm{C}$ & [95] XAS \\
\hline$(\mathrm{Fe}, \mathrm{Co})$ & [288] XMCD \\
\hline$(\mathrm{Fe}, \mathrm{Pd})$ & [139] XMCD \\
\hline$(\mathrm{Fe}, \mathrm{Gd})$ & [293] XMCD \\
\hline$(\mathrm{Fe}, \mathrm{Tb})$ & [276] XMCD \\
\hline (Fe, Dy) & [90] XMCD \\
\hline (Fe, Co, Tb) & [30] XMCD \\
\hline (Fe, Co, Zr) & [117] XMCD \\
\hline$(\mathrm{Fe}, \mathrm{Ni}) / \mathrm{Co}$ & [242] XMCD \\
\hline $\mathrm{FeSi}_{x}$ & [19] XMCD - [168] XAS - [82] XAS \\
\hline $\mathrm{Fe}\left\langle\mathrm{SiO}_{2}\right\rangle$ & [168] XAS \\
\hline FeAl & [31] EELS \\
\hline $\mathrm{Fe}_{2}(\mathrm{~V}) \mathrm{Al}$ & [238] XMCD \\
\hline $\mathrm{Co}(\mathrm{Cr}, \mathrm{Fe}) \mathrm{Al}$ & [81] XMCD - [144] XMCD \\
\hline $\mathrm{CO}_{2} \mathrm{FeSi}_{2}$ & {$[14] \mathrm{XMCD}$} \\
\hline$(\mathrm{Zn}, \mathrm{Fe}) \mathrm{Se}$ & [54] XAS \\
\hline$(\mathrm{Fe}, \mathrm{Co}) \mathrm{SiNbBCu}$ & [103] XMCD \\
\hline $\mathrm{Ce}_{2} \mathrm{Fe}_{17}(\mathrm{Al})$ & [112] XMCD \\
\hline
\end{tabular}

complexes with only one ligand species, starting with chloride, oxygen. Section 6.2 discusses nitrogen or carbon, including cyanides.

\subsection{Iron chloride and oxygen complexes}

We introduce the field of coordination complexes with the iron chlorides. The combination of iron and chlorine provides four combinations of systems with iron valences $2+$ and $3+$ and respectively fourfold and six-fold coordination. All four iron chloride spectra have been simulated in detail with charge transfer multiplet calculations [281]. The experimental spectra are very similar to the corresponding bulk oxides [72]. Bonhommeau et al. [28] studied the solutions of $\mathrm{FeCl}_{3}$ and $\mathrm{FeCl}_{2}$ in methanol, ethanol and propan-1-ol. The solvated $\mathrm{Fe}^{3+}$ complex is found to exhibit octahedral symmetry, while a tetragonal symmetry is observed for $\mathrm{Fe}^{2+}$. All complexes are high-spin.

The acetylacetonate (acac) complex contains three acac molecules, which is a bidentate ligand with the chemical formula $\mathrm{CH}_{3}-\mathrm{CO}-\mathrm{CH}-\mathrm{CO}-\mathrm{CH}_{3}$, with the two oxygens binding to iron. Fig. 12 shows that the $\mathrm{Fe}(\mathrm{acac})_{3}$ spectrum is similar to the $\left[\mathrm{FeCl}_{6}\right]^{3-}$ indicating that iron is trivalent and octahedrally surrounded. $\mathrm{Fe}(\mathrm{ox})_{3}{ }^{3-}$ contains three oxalate $\left(\mathrm{CO}_{2}\right)_{2}{ }^{2-}$ ligands and has a similar spectrum to $\mathrm{Fe}(\mathrm{acac})_{3}$. Iron complexes with terephthalic acid (tpa) on a copper surface have been studied by Gambardella et al. [98]. Terephthalic acid is a $\left(\mathrm{CO}_{2}\left(\mathrm{C}_{6} \mathrm{H}_{4}\right) \mathrm{CO}_{2}\right)^{2-}$ molecule that binds to iron ions with both ends of the molecule. It forms two dimensional $\mathrm{Fe}(\mathrm{tpa})$ networks on a $\mathrm{Cu}(100)$ surface. XMCD experiments show that Fe(tpa) is magnetized in-plane. The axial position can bind to an oxygen molecule, which modifies the $2 \mathrm{p}$ XAS and $\mathrm{XMCD}$ spectra and re-orients the magnetization to an out-of-plane direction [98]. Takacs et al. [250] measured the 2p XAS spectra of the molecular magnet systems that contain a four metal center. The central metal atom is bridged via two oxygens to each of its three 


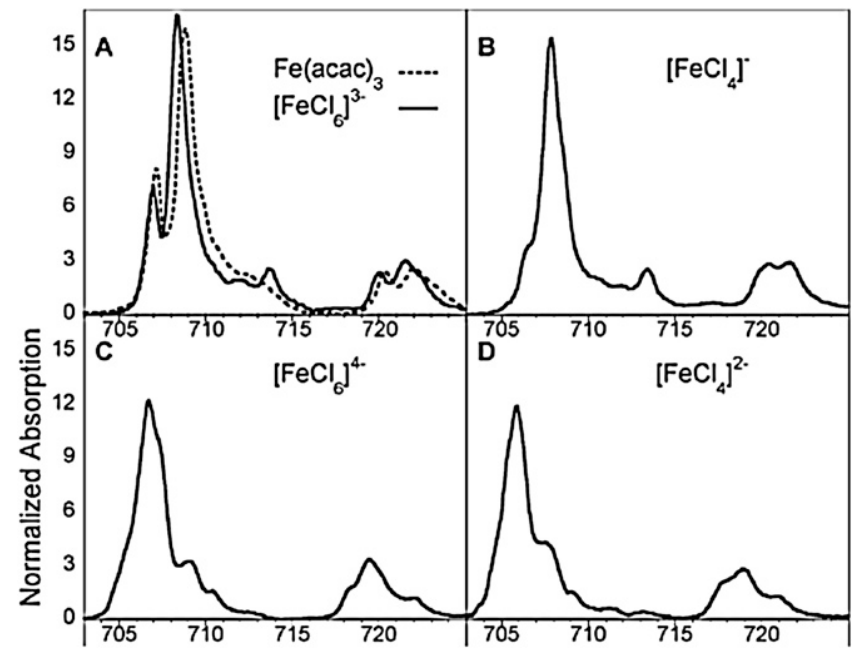

Fig. 12. $2 \mathrm{p}$ xas of $(\mathrm{A}) \mathrm{Fe}(\mathrm{acac})_{3},\left[\mathrm{FeCl}_{6}\right]^{3-}$, (B) $\left[\mathrm{FeCl}_{4}\right]^{-}$, (C) $\left[\mathrm{FeCl}_{6}\right]^{4-}$ and (D) $\left[\mathrm{FeCl}_{4}\right]^{2-}$. Taken from Wasinger [281].

iron neighbors, yielding a $\mathrm{Fe}_{4} \mathrm{O}_{6}$ core that is surrounded by oxygen coordinated ligands. Both the $\mathrm{FeO}_{6}-\mathrm{Fe}_{3}$ core and the $\mathrm{CrO}_{6}-\mathrm{Fe}_{3}$ core systems have been studied and from comparison to other experimental spectra a high-spin $\mathrm{Fe}^{2+}$ ground state is found for both systems (Table 7).

Peng et al. [218] measured 2p XAS and XMCD spectra of dinuclear iron-oxo complexes with different types of magnetic and electronic interactions between the iron sites. The spectra have been analyzed with ligand field multiplet theory. The XMCD spectra reveal the coupling between the two iron sites.

\subsection{Iron complexes with nitrogen and carbon}

In this section we discuss iron complexes with nitrogen and carbon ligands. Porphyrin and related heme-models with nitrogen ligands are discussed in the next section. The complexes of iron with 1,4,7-triazacyclononane ( $\operatorname{tacn}$ ) can be viewed as an isolated iron ion surrounded octahedrally by six nitrogens of the tacn groups. The $\mathrm{NH}$ nitrogens are linked together by two $\mathrm{CH}_{2}$ groups, yielding a system $\mathrm{Fe}\left[\left(\mathrm{CH}_{2} \mathrm{CH}_{2} \mathrm{~N}\right)_{3}\right]_{2}$. The valence of iron can be $2+$ or $3+$. Both systems are low-spin due to the large crystal field effect of the 6 nitrogens at short distance. The $2 \mathrm{p}$ XAS data can be reproduced in great detail from charge transfer multiplet calculations. An important aspect of the simulations is the different covalency for electrons in different 3d orbitals [281].

\section{Table 7}

The 2pXAS and 2pEELS papers of iron complexes with $\mathrm{Cl}$ and $\mathrm{O}$. This table is an extract from the full table that is maintained at the XASEELS database website.

\begin{tabular}{|c|c|}
\hline \multicolumn{2}{|c|}{ Iron complexes with $\mathrm{Cl}$ and $\mathrm{O} ; 2 \mathrm{p}$ XAS and $2 \mathrm{p}$ EELS spectra } \\
\hline$\left[\mathrm{FeCl}_{6}\right]^{3-}$ & [281] XAS \\
\hline$\left[\mathrm{FeCl}_{4}\right]^{-}$ & [281] XAS \\
\hline$\left[\mathrm{FeCl}_{6}\right]^{4-}$ & [281] XAS \\
\hline$\left[\mathrm{FeCl}_{6}\right]^{2-}$ & [281] XAS \\
\hline $\mathrm{FeCl}_{3} / \mathrm{CH}_{3} \mathrm{OH}$ & [28] XAS \\
\hline $\mathrm{FeCl}_{2} / \mathrm{CH}_{3} \mathrm{OH}$ & [28] XAS \\
\hline $\mathrm{Fe}(\mathrm{acac})_{3}$ & [281] XAS \\
\hline $\mathrm{Fe}\{\mathrm{tpa}\} / \mathrm{Cu}(100)$ & [98] XMCD - [84] XMCD \\
\hline$\left[\mathrm{Fe}-\mathrm{O}_{6}-\mathrm{Fe}_{3}\right]$ star & [163] XMCD - [250] XMCD - [192] XMCD \\
\hline$\left[\mathrm{Cr}-\mathrm{O}_{6}-\mathrm{Fe}_{3}\right]$ star & {$[250] \mathrm{XMCD}$} \\
\hline$\left\{\mathrm{Fe}_{8} \mathrm{Br}_{8}\right]$ magnet & [32] RIXS - [183] XMCD \\
\hline $\mathrm{Fe}_{4}\left\{\mathrm{~L}_{2}(\mathrm{DPM})_{6}\right\}$ & [193] XMCD \\
\hline $\mathrm{Fe}\{\mathrm{PNP}\}\{\mathrm{Cl}\}$ & [207] XAS \\
\hline$\left[\mathrm{Fe}_{2}(\mathrm{salmp})_{2}\right]$ & [218] XMCD \\
\hline
\end{tabular}

Table 8

The 2pXAS and 2pEELS papers of iron complexes with $\mathrm{N}, \mathrm{C}, \mathrm{CO}$ and $\mathrm{CN}$. This table is an extract from the full table that is maintained at the XASEELS database website (2010).

\begin{tabular}{ll} 
Iron complexes with $\mathrm{N}, \mathrm{C}, \mathrm{CO}$ and $\mathrm{CN} ; 2 \mathrm{p}$ XAS and 2p EELS spectra \\
\hline$\left[\mathrm{Fe}(\mathrm{tacn})_{2}\right] \mathrm{Cl}_{2}$ & {$[281]$ XAS $-[124]$ XAS } \\
$\mathrm{Fe}(\mathrm{tcne})_{2}$ & {$[24]$ XAS } \\
$\mathrm{Fe}(\mathrm{phen})_{2}(\mathrm{NCS})_{2}$ & {$[178]$ XAS $-[37]$ XAS $-[58]$ XAS } \\
$\mathrm{Fe}(\mathrm{tzpy})_{2}(\mathrm{NCS})_{2}$ & {$[236]$ XAS } \\
{$\left[\mathrm{Fe}\left(\mathrm{tren}(\mathrm{py})_{3}\right)\right]^{2+}$} & {$[132]$ XAS } \\
$\mathrm{Fe}(\mathrm{CO})_{5}$ & {$[282]$ EELS } \\
$\mathrm{Fe}(\mathrm{CO})_{3}(\mathrm{CN})_{2}$ & {$[104]$ XAS } \\
$\mathrm{Fe}(\mathrm{cp})_{2}$ & {$[282]$ EELS $-[212]$ XAS $-[216]$ XAS } \\
$\mathrm{Fe}\left(\mathrm{C}_{4} \mathrm{H}_{6}\right)(\mathrm{CO})_{3}$ & {$[282]$ EELS } \\
$\mathrm{Fe}(\mathrm{cp}-\mathrm{COCH})_{2}$ & {$[212]$ XAS } \\
$\mathrm{Fe}\left(\mathrm{C}_{2} \mathrm{H}_{5} \mathrm{PO}_{3}\right)$ & {$[89]$ XAS } \\
$\mathrm{Fe}\{\mathrm{CN}\}$ & {$[10]$ XAS $-[59]$ XAS $-[274]$ XAS $-[124]$ XAS - } \\
& {$[61]$ XAS $-[104]$ XAS - [28] XAS - [212] XAS - } \\
$\mathrm{Fe}\left\{\mathrm{N}(\mathrm{CN})_{2}\right\}$ & {$[292]$ XAS - [44] XAS } \\
\end{tabular}

Thin film iron complexes with tetracyanoethylene (tcne) have been studied by Bhatt et al. [24]. tcne has four cyano groups attached to a central double bonded $\mathrm{C}=\mathrm{C}$ group, i.e. $(\mathrm{CN})_{2} \mathrm{C}=\mathrm{C}(\mathrm{CN})_{2}$. CTM simulations yield a $\mathrm{Fe}^{2+}$ ground state with a crystal field of $0.6 \mathrm{eV}$. We note that the simulation could be further improved by allowing spin-orbit split states to mix/add to the ground state, similar to many other high-spin octahedral $\mathrm{Fe}^{2+}$ systems, due to its ${ }^{5} \mathrm{~T}_{2}$ ground state.

Iron carbonyl $\mathrm{Fe}(\mathrm{CO})_{5}$ contains formally $\mathrm{Fe}^{0}$ with a $3 \mathrm{~d}^{8}$ ground state. The two $3 \mathrm{~d}$-holes are positioned in the empty $x^{2}-y^{2}$ orbital, yielding a low-spin $S=0$ ground state. A series of iron carbonyl species has been measured with EELS by Wen et al. [282]. They analyze the iron $2 p$ spectra in terms of molecular orbital effects. The first two features in the iron L edge are assigned to respectively the empty $3 \mathrm{~d}$-state and the lowest empty $\pi^{*}$-state that contains significant iron d-content. No detailed multiplet analysis has been applied yet to $\mathrm{Fe}(\mathrm{CO})_{5}$; a similar analysis as for the cyanide spectra would be necessary with the inclusion of both metal ligand charge transfer (MLCT) and ligand metal charge transfer (LMCT). Iron ferrocene systems have been studied by Otero et al. [212]. They analyzed the iron L edges with molecular orbitals. No multiplet calculations exist for these systems (Table 8).

The first detailed multiplet analysis of the 2p XAS spectra of transition metal cyanides has been given by Arrio et al. [10], with emphasis on the $\mathrm{Cr}^{3+}$ ions which show significant MLCT. They analyzed the iron $\mathrm{L}$ edge of $\mathrm{Fe}_{3}\left[\mathrm{Cr}(\mathrm{CN})_{6}\right]_{2}$. The iron $\mathrm{L}$ edge of this system can be simulated with a high-spin $\mathrm{Fe}(\mathrm{II})$ ground state. Iron cyanide complexes are much studied with respect to their molecular magnet properties. The spectral shape of the parent compounds $\mathrm{K}_{4}\left[\mathrm{Fe}(\mathrm{CN})_{6}\right]$ and $\mathrm{K}_{3}\left[\mathrm{Fe}(\mathrm{CN})_{6}\right]$ have been analyzed in detail by Hocking et al. [124]. Fig. 13 compares the iron 2p XAS spectra of $\mathrm{K}_{3}\left[\mathrm{Fe}(\mathrm{CN})_{6}\right]$ and $\left[\mathrm{Fe}(\operatorname{tacn})_{2}\right] \mathrm{Cl}_{3}$. Both systems contain low-spin $\mathrm{Fe}^{3+}$ with its ${ }^{2} \mathrm{~T}_{2}$ ground state. The $\mathrm{K}_{3}\left[\mathrm{Fe}(\mathrm{CN})_{6}\right]$ spectrum contains an extra peak at $\sim 712.5 \mathrm{eV}$ related to the metal-to-ligand charge transfer (MLCT) of the $3 d^{5}$ ground state with the $3 d^{4} L$ state. Both systems also contain significant ligand-to-metal charge transfer (LMCT) that however does not induce a visible peak structure. Bonhommeau et al. [29] study thin films of Prussian blue analogs. The analysis with both MLCT and/or LMCT yields good simulations of the spectral shapes. For each thin film, the proportion of the different oxidation states of $\mathrm{Co}, \mathrm{Fe}$ and $\mathrm{Mn}$ is found to be different. Coronado et al. [61] study the pressure-induced magnetic switching and observe valence and spin changes in the iron state. 


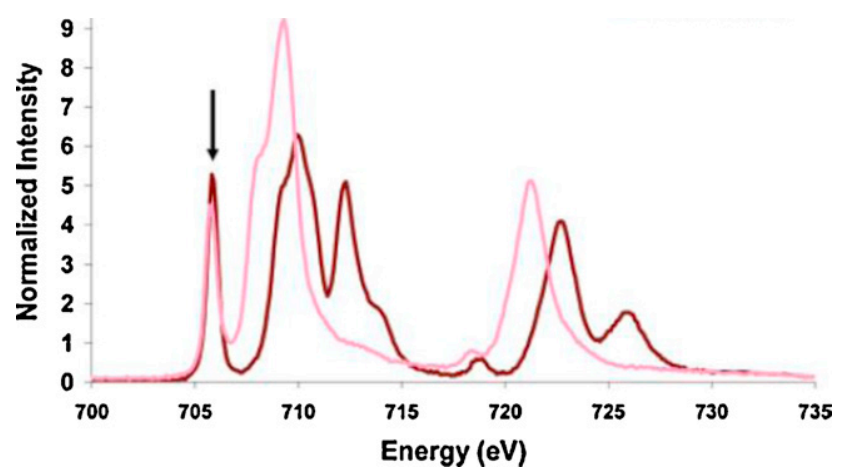

Fig. 13. The $2 p$ XAS spectra of the low spin $\mathrm{Fe}^{3+}$ system $\mathrm{K}_{3} \mathrm{Fe}(\mathrm{CN})_{6}$ (brown) and $\mathrm{Fe}(\mathrm{tacn})_{2} \mathrm{CL}_{3}$ (light pink). The MLCT induced peak appears at $712.5 \mathrm{eV}$, [124]. (For interpretation of the references to color in this figure legend, the reader is referred to the web version of the article.)

\subsection{Application V: spin cross-over systems}

A number of six-coordinate iron(II) complexes exhibit a spin transition (ST) when the iron coordination is affected by the temperature, pressure, light, or the modification of solvent molecules. A typical example of such systems is $\mathrm{FeL}_{2}(\mathrm{NCS})_{2}$. Lee et al. [178] studied the spin-crossover transition from, ${ }^{5} \mathrm{~T}_{2}, S=2$ (high spin, HS) $\rightarrow{ }^{1} \mathrm{~A}_{1}, S=0$ (low spin, LS) of the molecular complex, $\mathrm{Fe}(\mathrm{phen})_{2}(\mathrm{NCS})_{2}$; phen $=1,10$-phenanthroline. The crystal field multiplet simulation, assuming an $O_{h}$ symmetry at the Fe atom, gives rise to a $10 \mathrm{Dq}=0.9$ and $2.2 \mathrm{eV}$, respectively, for the high-spin respectively low-spin ground state. The addition of a metal-toligand charge transfer (MLCT) factor is important for fitting of some fine details of peak profile. The triazole-based ligand 3-(2-pyridyl) $[1,2,3]$ triazolo[1,5-a]pyridine) (tzpy) was studied by Sheu et al. [236]. This system shows Light-induced excited spin state trapping of the metastable high-spin state. This system shows large changes in the iron L edges that have only been analyzed in terms of its high-spin respectively low-spin state.

Huse et al. studied the spin transition in the iron polypyridyl complex $\left.\mathrm{Fe}\left(\operatorname{tren}(\mathrm{py})_{3}\right)\right]^{2+}$ (where tren(py) ${ }_{3}$ is tris(2pyridylmethyliminoethyl)amine) [132]. This study is performed with the iron complex dissolved using a liquid flow cell. The $2 \mathrm{p}$ XAS experiment is performed with $90 \mathrm{ps}$ time resolution and the high-spin ground state is found after 90 ps. Recently the time-resolution of this experiment has been improved to $700 \mathrm{fs}$ [133].

\subsection{Theory E: square planar symmetry}

A special feature of coordination compounds is the common occurrence of square planar symmetry, in particular in relation to the heme protein and models thereof. Square planar symmetry implies that the charge transfer multiplet calculations must be performed in tetragonal $\left(\mathrm{D}_{4 \mathrm{~h}}\right)$ symmetry. One important consequence is the stabilization of intermediate spin ground states. For $\mathrm{Fe}^{2+}$ in octahedral symmetry only $S=2$ high-spin and $S=0$ low-spin systems are found. In square planar symmetry the $S=1$ intermediate spin state is a common ground state. We introduce some consequences of $\mathrm{D}_{4 \mathrm{~h}}$ symmetry.

The elongation of the $z$-axis in an octahedral system brings the system in tetragonal symmetry $\left(D_{4 h}\right)$, with the extreme case of a square planar symmetry. The $3 \mathrm{~d}$ states that split into $\mathrm{T}_{2 \mathrm{~g}}$ and $E_{g}$ subsets in octahedral symmetry split further into four different symmetry states. The $E_{g}$ subset splits into $A_{1 g}$ and $B_{1 g}$ and the $T_{2 g}$ subset splits into $A_{2 g}$ and the double degenerate $E_{g}$ states, with only the $x z$ and $y z$ orbitals remaining degenerate. Within the charge transfer multiplet calculations, the Hamiltonian in $\mathrm{D}_{4 \mathrm{~h}}$ symmetry

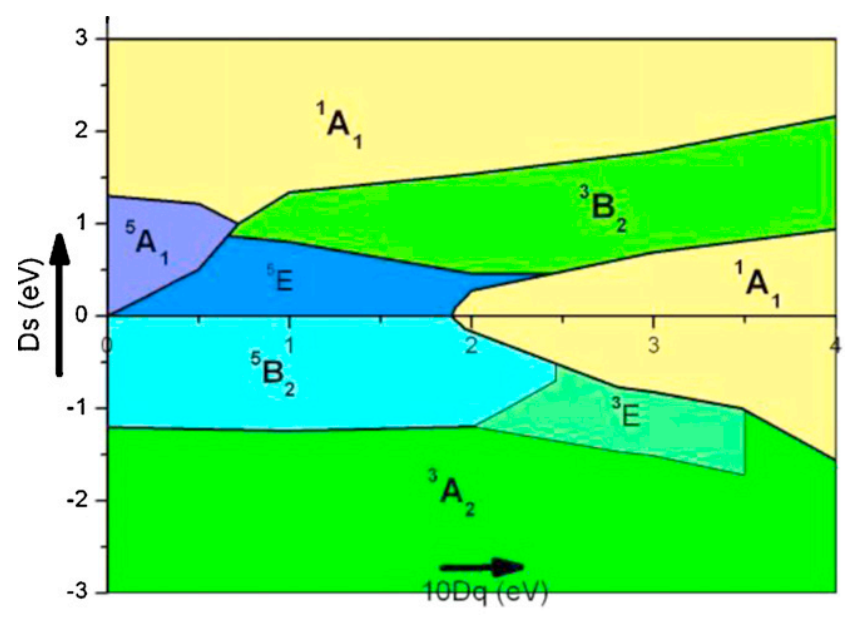

Fig. 14. Phase diagram for the ground state of $\mathrm{Fe}^{2+}$ as a function of $10 \mathrm{Dq}$ and $\mathrm{Ds}$. The high-spin ground states $\left({ }^{5} \mathrm{~A}_{1},{ }^{5} \mathrm{E}\right.$ and $\left.{ }^{5} \mathrm{~B}_{2}\right)$ are indicated in blue, intermediate spin $\left({ }^{3} \mathrm{~A}_{2},{ }^{3} \mathrm{~B}_{2}\right.$ and $\left.{ }^{3} \mathrm{E}\right)$ in green and low-spin $\left({ }^{1} \mathrm{~A}_{1}\right)$ in yellow. (For interpretation of the references to color in this figure legend, the reader is referred to the web version of the article.)

has a total of three terms with the corresponding radial parameters indicated as $\mathrm{X}_{400}, \mathrm{X}_{420}$ and $\mathrm{X}_{220}$. These three branching parameters are linearly related to the $10 \mathrm{Dq}$, Ds and Dt parameters as used in optical spectroscopy. They determine together the distortion from octahedral symmetry. The two common Fe valences are $\mathrm{Fe}^{2+}$ and $\mathrm{Fe}^{3+}$. The $3 \mathrm{~d}^{6}$ ground state of $\mathrm{Fe}^{2+}$ can, in principle, consist in high-spin $S=2$, intermediate-spin $S=1$ and low-spin $S=0$ ground states. Similarly the $3 \mathrm{~d}^{5}$ ground state of $\mathrm{Fe}^{3+}$ can have a high-spin $S=5 / 2$, intermediate-spin $S=3 / 2$ and low-spin $S=1 / 2$ ground states In octahedral symmetry only high-spin and low-spin systems occur and also in most distorted cubic systems either high-spin or lowspin systems are found. Square planar symmetry causes the $x^{2}-y^{2}$ orbital to be high in energy, much higher than all other orbitals. This effectively turns $\mathrm{Fe}^{2+}$ and $\mathrm{Fe}^{3+}$ systems into a potential intermediate spin state system.

By varying the values for 10Dq, Ds and Dt one can create all possible relative energy orderings between the $3 \mathrm{~d}$ orbitals, thereby creating high-spin, low-spin and intermediate-spin ground states for both $\mathrm{Fe}^{3+}$ and $\mathrm{Fe}^{2+}$. For octahedral symmetry the high-spin to low-spin transition is found at $10 \mathrm{Dq} \sim 1.9 \mathrm{eV}$ for $\mathrm{Fe}^{2+}$ and at $10 \mathrm{Dq}$ $\sim 3.2 \mathrm{eV}$ for $\mathrm{Fe}^{3+}$, using atomic electrostatic interactions. In case of covalent systems, the electrostatic interactions are, effectively, reduced, implying transitions to low-spin at lower $10 \mathrm{Dq}$ values. For ionic octahedral symmetry an intermediate spin ground state does not exist. In $\mathrm{D}_{4 \mathrm{~h}}$ symmetry, by using a Ds value, several intermediate and several high-spin states can be reached as seen in the following crystal field phase diagram.

Fig. 14 shows a phase diagram of the ground states of an ionic $\mathrm{Fe}^{2+}$ system, using atomic electrostatic interactions. The $3 \mathrm{~d}$ spin-orbit coupling has been set to zero, which creates sharp transition points between the various spin symmetries. Inclusion of the $3 \mathrm{~d}$ spin-orbit coupling complicates the transitions by creating quantum-chemical mixtures of two or more configurations, yielding mixed-spin ground state close to transition points. A more complete study of the ground states, including the variation of the Dt parameters has been published in the $\mathrm{PhD}$ thesis of Piter Miedema [200].

One can observe that at low $10 \mathrm{Dq}$, a small positive Ds yields a ${ }^{5} \mathrm{E}$ ground state and a small negative Ds a ${ }^{5} \mathrm{~B}_{2}$ ground state. The ${ }^{5} \mathrm{E}$ ground state has all spin-up states filled with the sixth electron filling the E-symmetry state. Exactly at Ds $=0$, both ground states are degenerate and the ground state, in now octahedral symmetry, is ${ }^{5} \mathrm{~T}_{2}$. At a crystal field of $1.9 \mathrm{eV}$ the transition to the low-spin 
Table 9

Electronic ground state of $\mathrm{Fe}^{2+}$ and their occupation numbers (rounded to an integer value) of the different (in $\mathrm{D}_{4 \mathrm{~h}}$ split) 3d-orbitals.

\begin{tabular}{llll}
\hline States & Occupied orbitals & State & Occupied orbitals \\
\hline${ }^{5} \mathrm{E}$ & $\mathrm{e}^{3} \mathrm{a}_{1}{ }^{1} \mathrm{~b}_{2}{ }^{1} \mathrm{~b}_{1}{ }^{1}$ & ${ }^{3} \mathrm{E}_{\mathrm{a}}$ & $\mathrm{e}^{3} \mathrm{a}_{1}{ }^{1} \mathrm{~b}_{2}{ }^{2}$ \\
${ }^{5} \mathrm{~B}_{2}$ & $\mathrm{e}^{2} \mathrm{~b}_{1}{ }^{1} \mathrm{~b}_{2}{ }^{2} \mathrm{~b}_{1}{ }^{1}$ & ${ }^{3} \mathrm{E}_{\mathrm{b}}$ & $\mathrm{e}^{3} \mathrm{a}_{1}{ }^{2} \mathrm{~b}_{2}{ }^{1}$ \\
${ }^{5} \mathrm{~A}_{1}$ & $\mathrm{e}^{2} \mathrm{a}_{1}{ }^{2} \mathrm{~b}_{2}{ }^{1} \mathrm{~b}_{1}{ }^{1}$ & ${ }^{3} \mathrm{~A}_{2}$ & $\mathrm{e}^{2} \mathrm{a}_{1}{ }^{2} \mathrm{~b}_{2}{ }^{2}$ \\
${ }^{1} \mathrm{~A}_{1}$ & $\mathrm{e}^{4} \mathrm{a}_{1}{ }^{2}$ or $\mathrm{e}^{4} \mathrm{~b}_{2}{ }^{2}$ & ${ }^{3} \mathrm{~B}_{2}$ & $\mathrm{e}^{4} \mathrm{a}_{1}{ }^{1} \mathrm{~b}_{2}{ }^{1}$
\end{tabular}

${ }^{1} \mathrm{~A}_{1}$ ground state occurs. One observes that at negative Ds values below $-1.2 \mathrm{eV}$, the ground state is the intermediate spin ${ }^{3} \mathrm{~A}_{2}$ state. The ${ }^{3} \mathrm{E}$ and ${ }^{3} \mathrm{~B}_{2}$ intermediate spin ground state can also be found at (10Dq, Ds) combinations as indicated in Figure. Table 9 gives the (main) occupation of the 3d-orbitals for the various symmetry states. Due to spin-orbit coupling and 3d3d electrostatic interactions these occupations are not $100 \%$ pure. In fact each symmetry state relates to a number of orbital occupations, where Table 9 gives the dominant ones.

\subsection{Application VI: phthalocyanine, porphyrin and related systems}

In this section we discuss the $2 \mathrm{p}$ XAS spectra of iron in phthalocyanine (Pc) and porphyrin rings, which also includes the iron center in heme, as indicated in Fig. 15. FePc was one of the first systems that have been calculated with crystal field multiplet calculations by Thole et al. [258]. The found two potential ground states, respectively the ${ }^{3} \mathrm{E}$ intermediate spin ground state (with a ${ }^{5} \mathrm{~A}_{1}$ excited state at $8 \mathrm{meV}$ higher and ${ }^{3} \mathrm{~A}_{2}$ excited state at $58 \mathrm{meV}$ ) or the ${ }^{5} A_{1}$ ground state (with the ${ }^{3} B_{2}$ and ${ }^{3} E$ excited states at respectively $3 \mathrm{meV}$ and $12 \mathrm{meV}$ ). From these low excitation energies, it is clear that the ground state in iron porphyrin has a large flexibility in ground state symmetries depending on the detailed surroundings. A recent calculation of Miedema et al. [199] confirms the ${ }^{3} \mathrm{E}$ intermediate spin ground state for the bulk FePc system (Table 10).

Bernien et al. [20] measured the $\mathrm{Fe}^{3+}$ octaethylporphyrin (oep) molecules on cobalt and on nickel surfaces. The XMCD spectra show significant fine structure. Hocking et al. [125] measured the iron Tetraphenylporphyrin (tpp) systems $\left[\mathrm{Fe}(\mathrm{tpp})(\operatorname{ImH})_{2}\right]$ and $\left[\mathrm{Fe}(\mathrm{tpp})(\mathrm{ImH})_{2}\right] \mathrm{Cl}$. CTM analysis confirms that the ground states are respectively low $\mathrm{Fe}^{2+}$ and low spin $\mathrm{Fe}^{3+}$. Hocking et al. [123] also measured the corrole system $\mathrm{Fe}(\mathrm{tdcc})(\mathrm{py})_{2}$ where tdcc is a trianion of 5,10,15-tris-(2,6-dichlorophenyl)corrole)) The corrole cycle has one carbon less compared with porphyrin. They conclude that the contracted corrole is both a stronger $\sigma$ donor and a very anisotropic
Table 10

The 2pXAS and 2pEELS papers of iron phthalocyanine and porphyrins complexes. This table is an extract from the full table that is maintained at the XASEELS database website (2010).

\begin{tabular}{ll}
\hline \multicolumn{2}{l}{ Iron phthalocyanine and porphyrin complexes; 2p XAS and 2p EELS spectra } \\
\hline FePc & {$[152]$ XAS $-[258]$ CALC $-[199]$ XAS $-[240]$ XAS } \\
FePc/Au & {$[15]$ XMCD $-[246]$ XMCD } \\
Fe $\{$ porphyrin $\} / C o$ & {$[20]$ XMCD $-[284]$ XMCD $-[21]$ XMCD $-[201]$ XMCD } \\
$\mathrm{Fe}\{$ Hb $\}$ & {$[125]$ XAS $-[13]$ XAS } \\
$\mathrm{Fe}\{$ catalase $\}: H 2 O:$ & {$[18]$ XAS } \\
$\mathrm{Fe}\{$ corrole $\}$ & {$[123]$ XAS } \\
Fe $\{$ Mb $\}$ & {$[277]$ XAS $-[278]$ XAS $-[94]$ XMCD } \\
\hline
\end{tabular}

Table 11

The 2pXAS and 2pEELS papers of iron sulfur and phosphorus complexes. This table is an extract from the full table that is maintained at the XASEELS database website (2010).

\begin{tabular}{lc} 
Iron sulfur and phosphorus complexes; 2p XAS and 2p EELS spectra \\
\hline Rubredoxin $(\mathrm{Fe}) \mathrm{S}_{4}$ & {$[105]-\mathrm{XAS}$} \\
Ferrodoxin $\left(\mathrm{Fe}_{2} \mathrm{~S}_{2}\right) \mathrm{S}_{4}$ & {$[272]-\mathrm{XAS}$} \\
$\mathrm{Fe}-\left(\mathrm{S}_{2} \mathrm{P}_{2} \mathrm{C}_{2}\right)$ & {$[104]-\mathrm{XAS}$} \\
$\mathrm{Fe}-\left(\mathrm{NP}_{3}\right)$ & {$[104]-\mathrm{XAS}$} \\
\hline
\end{tabular}

$\pi$ donor, which decrease the bonding interactions with axial ligands and contribute to the increased axial ligand lability and reactivity of ferric corroles relative to ferric porphyrins. Aziz et al. [13] measured the $2 \mathrm{p}$ XAS spectrum of the hemoglobin iron center in physiological solutions. They find different spectra in solution as compared with the solid state and conclude that the iron ground state is high-spin. Wang et al. [278] show the effects of photolysis on the Myoglobin CO system (FeMbCO). The photolysed products has a low-spin ground state, modified from a high-spin ground state in the parents FeMbCO system.

\subsection{Iron sulphur and phosphor complexes and proteins}

George et al. [105] measured the 2p XAS spectrum of Pyrococcus furiosus rubredoxin. Rubredoxins are small proteins which contain single iron atoms coordinated by a distorted tetrahedron of cysteinyl sulfur ligands. This makes it the simplest iron-sulfur protein. For the simulations the covalency of the $\mathrm{S}$ ligands is reflected in additional reductions of the Slater integrals (70\% instead of $80 \%$ ). Both simulations for the oxidized and reduced rubredoxin are performed, giving for the oxidized form $10 \mathrm{Dq}-0.75 \pm 0.1 \mathrm{eV}$ for $\mathrm{Fe}^{3+}$ and for the reduced form $10 \mathrm{Dq}=-0.60 \pm 0.1 \mathrm{eV}$ for $\mathrm{Fe}^{2+}$. Van Elp et al. [272] measured the 2p XAS and XMCD spectra of the $\mathrm{Fe}_{2} \mathrm{~S}_{2}$

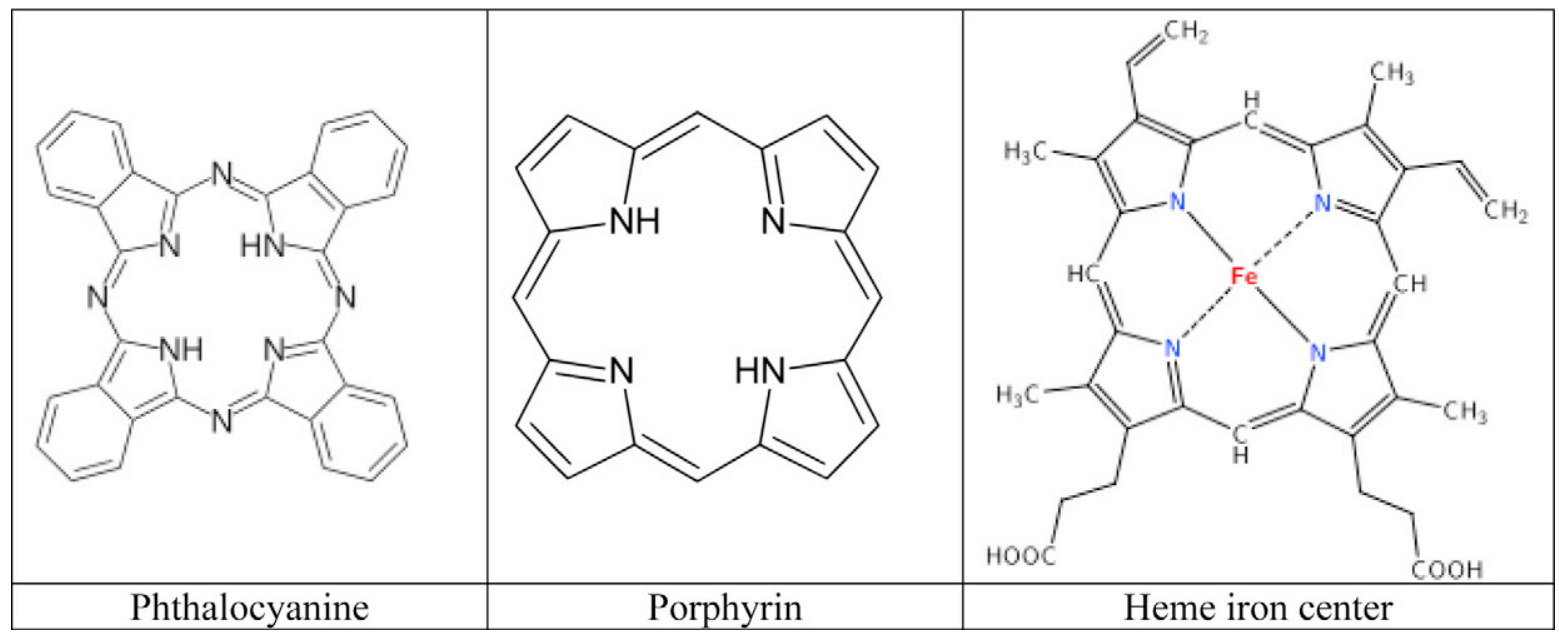

Fig. 15. The molecular structures of phthalocyanine, porphyrins and the heme iron center. 
center in C. pasteurianum ferredoxin. The analysis focuses on the effects of the zero field splitting on the antiferromagnetic coupling. A number of iron systems with sulfur and phosphorus ligands have been measured by George et al. [104] (Table 11).

\section{Concluding remarks}

In this review we have discussed the iron $2 \mathrm{p}$ X-ray absorption spectroscopy (XAS) and electron energy loss spectroscopy (EELS) spectra of iron materials, with emphasis on the spectral shape and on the fundamental studies to reveal and interpret this spectral shape. We will keep and updated database of all iron 2p XAS and $2 p$ EELS spectra. This database will contain publications, but also spectra in digital form and links to dedicated EELS groups and XAS beam lines that are important for 2p XAS and 2p EELS analysis.

We have seen that 2p X-ray absorption of transition metal systems provides typical multi-peaked spectra dominated by atomic multiplet effects. The large amount of structure allows the possibility to obtain detailed information on the local symmetry of the transition metal system. Due to the charge conservation in the initial step of 2p X-ray absorption chemical bonding information is less directly obtained. A combination with an ionizing experiment such as 2 p XPS is necessary to obtain also detailed information on hybridization and charge transfer effects.

The 2p XAS spectra of covalent systems contain little fine structure. This implies that not much detail regarding the electronic structure can be obtained for metallic and covalent systems. XMCD experiments provide information of the spin and orbital moment. Much more information can be obtained with resonant inelastic $\mathrm{X}$-ray scattering and diffraction for which the spectroscopy involving the same atoms and actually the same excitations becomes very rich and full of detailed fine structure not visible in the XAS spectra.

Another important extension of 2p X-ray absorption and EELS is the combination with microscopy. TXM-XAS and STEM-EELS are very powerful spectromicroscopic techniques that combine respectively $0.1-10 \mathrm{~nm}$ spatial resolution with elemental and chemical mapping.

\section{References}

[1] (2010), XASEELS website, www.anorg.chem.uu.nl/xaseels/

[3] M. Abbate, F.M.F. de Groot, J.C. Fuggle, et al., Phys. Rev. B 46 (8) (1992) 4511-4519.

[4] M. Abbate, L. Mogni, F. Prado, et al., Phys. Rev. B 71 (19) (2005).

[5] M. Abbate, G. Zampieri, J. Okamoto, et al., Phys. Rev. B 65 (16) (2002)

[6] A. Agui, M. Mizumaki, Y.Saitoh, et al., J. Synchrotron Radiat. 8 (2001)907-909.

[7] A.D. Alvarenga, F. Garcia, L.C. Sampaio, et al., J. Magn. Magn. Mater. 233 (1-2) (2001) 74-77.

[8] S. Andrieu, M. Finazzi, F. Yubero, et al., Europhys. Lett. 38 (6) (1997) 459-464.

[9] E. Arenholz, G. van der Laan, R.V. Chopdekar, et al., Phys. Rev. B 74 (9) (2006) 094407.

[10] M.A. Arrio, P. Sainctavit, C.C.D. Moulin, et al., J. Am. Chem. Soc. 118 (27) (1996) 6422-6427.

[11] M. Atanasov, R.H. Potze, G.A. Sawatzky, J. Solid State Chem. 119 (2) (1995) 380-393.

[12] A. Augustsson, G.V. Zhuang, S.M. Butorin, et al., J. Chem. Phys. 123 (18) (2005).

[13] E.F. Aziz, N. Ottosson, S. Bonhommeau, et al., Phys. Rev. Lett. 102 (6) (2009).

[14] B. Balke, S. Wurmehl, G.H. Fecher, et al., Sci. Technol. Adv. Mater. 9 (1) (2008).

[15] F. Bartolomé, L.M. García, G. Filoti, et al., Phys. Rev. B. 81 (2010) 195405.

[16] A. Bashir, M. Ikram, R. Kumar, et al., J. Phys. Condens. Matter 21 (32) (2009) 325501.

[17] H. Bea, M. Bibes, S. Fusil, et al., Phys. Rev. B 74 (2) (2006) 020101.

[18] N. Bergmann, S. Bonhommeau, K.M. Lange, et al., Phys. Chem. Chem. Phys. 12 (2010) 4827.

[19] D. Berling, G. Gewinner, M. Hanf, et al., J. Magn. Magn. Mater. 191 (3) (1999) $331-338$.

[20] M. Bernien, X. Xu, J. Miguel, et al., Phys. Rev. B 76 (21) (2007) 214406

[21] M. Bernien, J. Miguel, C. Weis, et al., Phys. Rev. Lett. 102 (4) (2009) 047202.

[22] M. Besse, V. Cros, A. Barthelemy, et al., Europhys. Lett. 60 (4) (2002) 608-614.

[23] J.S. Bettinger, C. Piamonteze, R.V. Chopdekar, et al., Phys. Rev. B 80 (14) (2009) 140413.

[24] P. Bhatt, E. Carlegrim, A. Kanciurzewska, et al., Appl. Phys. A-Mater. Sci. Process. 95 (1) (2009) 131-138.
[25] P.E.R. Blanchard, B.R. Slater, R.G. Cavell, et al., Solid State Sci. 12 (1) (2010)

[26] G. Boero, S. Mouaziz, S. Rusponi, et al., New J. Phys. 10 (2008) 16.

[27] F. Bondino, E. Magnano, C.H. Booth, et al., Phys. Rev. B 82 (1) (2010) 014529.

[28] S. Bonhommeau, N. Ottosson, W. Pokapanich, et al., J. Phys. Chem. B 112 (40) (2008) 12571-12574

[29] S. Bonhommeau, N. Pontius, S. Cobo, et al., Phys. Chem. Chem. Phys. 10 (38) (2008) 5882-5889.

[30] C. Bordel, S. Pizzini, J. Vogel, et al., Phys. Rev. B 56 (13) (1997) 8149-8155.

[31] G.A. Botton, C.J. Humphreys, Intermetallics 7 (7) (1999) 829-833.

[32] D. Boukhvalov, E. Kurmaev, A. Moewes, et al., J. Electron Spectrosc. Relat. Phenom. 137 (2004) 735-739.

[33] L. Braicovich, G. van der Laan, A. Tagliaferri, et al., Phys. Rev. B 75 (18) (2007) 184408.

[34] A. Braun, Q. Chen, D. Flak, et al., ChemPhysChem 13 (12) (2012) 2937-2944.

[35] S. Brice-Profeta, M. Arrio, E. Tronc, et al., J. Magn. Magn. Mater. 288 (2005) 354-365.

[36] M.G. Brik, J. Phys. Chem. Solids 69 (2008) 2568-2577.

[37] V. Briois, C. Cartier Dit Moulin, P. Sainctavit, et al., J. Am. Chem. Soc. 117 (3) (1995) 1019-1026.

[38] S. Brueck, M. Paul, H. Tian, et al., Appl. Phys. Lett. 100 (8) (2012) 081603.

[39] S.J. Brotton, R. Shapiro, G. van der Laan, et al., J. Geophys. Res. Biogeosci. 112 (G3) (2007) G03004.

[40] S.M. Butorin, J. Electron Spectrosc. Relat. Phenom. 110-111 (2000) 213-233.

[41] J.M. Byrne, N.D. Telling, V.S. Coker, et al., Nanotechnology 22 (45) (2011) 455709.

[42] C.C. Calvert, A. Brown, R. Brydson, J. Electron Spectrosc. Relat. Phenom. 143 (2-3) (2005) 173-187.

[43] P. Carra, B.T. Thole, M. Altarelli, X.D. Wang, Phys. Rev. Lett. 70 (1993) 694.

[44] C. Cartier dit Moulin, F. Villain, A. Bleuzen, et al., J. Am. Chem. Soc. 122 (28) (2000) 6653-6658.

[45] C. Carvallo, P. Sainctavit, M. Arrio, et al., Am. Mineral. 93 (5-6) (2008) 880-885.

[46] J.M. Charnock, C.M.B. Henderson, J.F.W. Mosselmans, et al., Phys. Chem. Miner 23 (7) (1996) 403-408.

[47] L. Chang, R.A.D. Pattrick, G. van der Laan, et al., Can. Mineral. 50 (3) (2012) 667-674.

[48] C.-- Chen, B. Moritz, F. Vernay, et al., Phys. Rev. Lett. 105 (17) (2010) 177401

[49] C.L. Chen, G. Chern, W.L. Pan, et al., J. Electron Spectrosc. Relat. Phenom. 144-147 (2005) 921-923.

[50] C.T. Chen, Y.U. Idzerda, H.J. Lin, et al., Phys. Rev. Lett. 75 (1) (1995) 152-155.

[51] C.T. Chen, F. Sette, Phys. Scr. T31 (1990) 119-126.

[52] S.-. Chen, A. Gloter, A. Zobelli, et al., Phys. Rev. B 79 (2009) 104103.

[53] C.L. Chen, C.L. Dong, J.L. Chen, et al., Phys. Chem. Chem. Phys. 13 (34) (2011) 15666-15672.

[54] K. Cho, H. Koh, J. Park, et al., Phys. Rev. B Condens. Matter Mater. Phys. 63 (15) (2001) 1552031-1552037.

[55] J. Claydon, Y. Xu, M. Tselepi, et al., Phys. Rev. Lett. 93 (3) (2004) 037206.

[56] V.S. Coker, C.I. Pearce, C. Lang, et al., Eur. J. Mineral. 19 (5) (2007) 707-716.

[57] V.S. Coker, J.M. Byrne, N.D. Telling, et al., Geobiology 10 (4) (2012) 347-354.

[58] D. Collison, C. Garner, C. McGrath, et al., J. Chem. Soc. Dalton Trans. 22 (1997) 4371-4376.

[59] D. Collison, C. Garner, C. McGrath, et al., J. Synchrotron Radiat. 6 (1999) 585-587.

[60] C. Colliex, T. Manoubi, C. Ortiz, Phys. Rev. B 44 (20) (1991) 11402-11411.

[61] E. Coronado, M.C. Gimenez-Lopez, T. Korzeniak, et al., J. Am. Chem. Soc. 130 (46) (2008) 15519-15532.

[62] R.D. Cowan, The Theory of Atomic Structure and Spectra, University of California Press, Berkeley, 1981.

[63] G. Cressey, C.M.B. Henderson, G. van der Laan, Phys. Chem. Miner. 20 (1993) 111-119.

[64] J.P. Crocombette, M. Pollak, F. Jollet, et al., Phys. Rev. B 52 (5) (1995) 3143-3150.

[65] V. Cros, F. Petroff, J. Vogel, et al., Europhys. Lett. 49 (6) (2000) 807-813.

[66] S. Czekaj, F. Nolting, L. Heyderman, et al., Phys. Rev. B 73 (2) (2006) 020401.

[67] K. Deboudt, A. Gloter, A. Mussi, et al., J. Geophys. Res. Atmos. 117 (2012) D12307.

[68] F.M.F. de Groot, J.C. Fuggle, B. Thole, et al., Phys. Rev. B 42 (9) (1990) 5459-5468.

[69] F.M.F. de Groot, J. Elec. Spec. 67 (1994) 529.

[70] F.M.F. de Groot, Z.W. Hu, M.F. Lopez, G. Kaindl, et al., J. Chem. Phys. 101 (1994) 6570.

[71] F.M.F. de Groot, Chem. Rev. 101 (2001) 1779-1808.

[72] F.M.F. de Groot, P. Glatzel, U. Bergmann, et al., J. Phys. Chem. B 109 (44) (2005) 20751-20762.

[73] F.M.F. de Groot, Coor. Chem. Rev. 249 (2005) 31.

[74] F. de Groot, A. Kotani, Core Level Spectroscopy of Solids, Taylor and Francis, New York, 20083.

[75] F.M.F. de Groot, E. de Smit, M.M. van Schooneveld, et al., ChemPhysChem 11 (5) (2010) 951-962.

[76] E. de Smit, J.F. Creemer, H. Zandbergen, et al., J. Phys. Conf. Ser. 190 (2009) 012161.

[77] E. de Smit, I. Swart, J.F. Creemer, et al., Nature 456 (7219) (2008) U39-U222.

[78] M.A. de Vries, T.K. Johal, A. Mirone, et al., Phys. Rev. B 79 (2009) 045102.

[79] A. Deb, M. Mizumaki, T. Muro, et al., Phys. Rev. B 68 (1) (2003). 
[80] T. Droubay, G. Mursky, B.P. Tonner, J. Electron Spectrosc. Relat. Phenom. 84 (1-3) (1997) 159-169.

[81] H.J. Elmers, G.H. Fecher, D. Valdaitsev, et al., Phys. Rev. B Condens. Matter Mater. Phys. 67 (10) (2003) 104412.

[82] F. Esaka, H. Yamamoto, H. Udono, et al., Appl. Surf. Sci. 257 (7) (2011) 2950-2954.

[83] D.J. Fabian, L.M. Watson, C.A.W. Marshall, Rep. Prog. Phys. 34 (1971) 28

[84] S. Fabris, S. Stepanow, N. Lin, et al., Nano Lett. 11 (12) (2011) 5414-5420.

[85] D. Faivre, P. Agrinier, N. Menguy, et al., Geochim. Cosmochim. Acta 68 (21) (2004) 4395-4403.

[86] M. Faiz, A. Mekki, M.S. Kariapper, et al., J. Non-Cryst. Solids 357 (22-23) (2011) 3803-3806

[87] A. Feldhoff, J. Martynczuk, M. Arnold, et al., J. Solid State Chem. 182 (11) (2009) 2961-2971.

[88] J. Fink, T. Muller-Heinzerling, B. Scheerer, et al., Phys. Rev. B Condens. Matter 32 (8) (1985) 4899-4904.

[89] L. Finkelstein, P. Postnikov, E. Kurmaev, et al., Phys. Rev. B 63 (7) (2001) 075113.

[90] K. Fleury-Frenette, S. Dhesi, G. van der Laan, et al., J. Magn. Magn. Mater. 220 (1) (2000) 45-51.

[91] B. Freelon, Y. Liu, C.R. Rotundu, et al., J. Phys. Soc. Jpn. 79 (7) (2010) 074716

[92] D. Frost, F. Langenhorst, P. van Aken, Phys. Chem. Miner. 28 (7) (2001) 455-470.

[93] T. Fuji, M. Yamashita, S. Fujimori, et al., J. Magn. Magn. Mater. 310 (2) (2007) E555-E557.

[94] T. Funk, A. Deb, S.J. George, et al., Coord. Chem. Rev. 249 (2005) 3-30.

[95] V.R. Galakhov, A.S. Shkvarin, A.S. Semenova, et al., J. Phys. Chem. C 114 (51) (2010) 22413-22416.

[96] V.R. Galakhov, E.Z. Kurmaev, K. Kuepper, et al., J. Phys. Chem. C 114(11)(2010) 5154-5159.

[97] P. Gambardella, S.S. Dhesi, S. Gardonio, et al., Phys. Rev. Lett. 88 (4) (2002).

[98] P. Gambardella, S. Stepanow, A. Dmitriev, et al., Nat. Mater. 8 (3) (2009) 189-193.

[99] L. Garvie, A. Craven, R. Brydson, Am. Mineral. 79 (5-6) (1994) 411-425.

[100] L. Garvie, P. Buseck, Nature 396 (6712) (1998) 667-670.

[101] L. Garvie, P. Buseck, Am. Mineral. 89 (4) (2004) 485-491.

[103] S. Gautam, S.N. Kane, B. Park, et al., J. Non-Cryst. Solids 357 (11-13) (2011) $2228-2231$

[104] S.J. George, J.X. Fu, Y.S. Guo, et al., Inorg. Chim. Acta 361 (4) (2008) 1157-1165.

[105] S.J. George, J. Van Elp, J. Chen, et al., J. Am. Chem. Soc. 114 (1992) 4426-4427.

[106] B. Gilbert, J.E. Katz, J.D. Denlinger, et al., J. Phys. Chem. C 114 (50) (2010) 21994-22001.

[107] A. Gloter, F. Guyot, I. Martinez, et al., Am. Mineral. 85 (10) (2000) 1452-1458

[108] A. Gloter, J. Ingrin, D. Bouchet, et al., Phys. Rev. B 61 (4) (2000) 2587-2594.

[109] A. Gloter, J. Ingrin, D. Bouchet, et al., Phys. Chem. Miner. 27 (7) (2000) 504-513.

[110] A. Gloter, M. Zbinden, F. Guyot, et al., Earth Planet. Sci. Lett. 222 (3-4) (2004) 947-957.

[111] S. Goh, A. Buckley, R. Lamb, et al., Geochim. Cosmochim. Acta 70 (9) (2006) 2210-2228.

[112] F. Grandjean, G. Waddill, T. Cummins, et al., Solid State Commun. 109 (12) (1999) 779-784.

[113] Y. Guan, C. Scheck, W.E. Bailey, J. Magn. Magn. Mater. 321 (8) (2009) 1039-1044.

[114] R. Gupta, S. Sen, Phys. Rev. B 12 (1) (1975) 15-19.

[115] Y.Guyodo, P. Sainctavit, M. Arrio, et al., Geochem. Geophys. Geosyst. 13 (2012) Q06Z44.

[116] S.W. Han, J. Kang, S.S. Lee, et al., J. Phys. Condens. Matter 18 (31) (2006) 7413-7426.

[117] T. Hase, H. Raanaei, H. Lidbaum, et al., Phys. Rev. B 80 (13) (2009) 134402.

[118] J.R. Hayes, A.P. Grosvenor, J. Phys. Condens. Matter 23 (46) (2011) 465502.

[119] W.M. Heijboer, A.A. Battiston, A. Knop-Gericke, et al., Phys. Chem. Chem. Phys. 5 (20) (2003) 4484-4491.

[120] W.M. Heijboer, A.A. Battiston, A. Knop-Gericke, et al., J. Phys. Chem. B 107 (47) (2003) 13069-13075.

[121] W. Heijboer, D. Koningsberger, B. Weckhuysen, et al., Catal. Today 110 (3-4) (2005) 228-238.

[122] J.F. Hochepied, P. Sainctavit, M.P. Pileni, J. Magn. Magn. Mater. 231 (2-3)(2001) 315-322.

[123] R.K. Hocking, S. DeBeer George, Z. Gross, et al., Inorg. Chem. 48 (4) (2009) 1678-1688.

[124] R.K. Hocking, E.C. Wasinger, F.M.F. de Groot, et al., J. Am. Chem. Soc. 128 (32) (2006) 10442-10451.

[125] R.K. Hocking, E.C. Wasinger, Y.L. Yan, et al., J. Am. Chem. Soc. 129 (1) (2007) 113-125.

[126] N. Hollmann, M. Valldor, H. Wu, et al., Phys. Rev. B 83 (18) (2011) 180405.

[127] H.M. Hollmark, T. Gustafsson, K. Edstrom, et al., Phys. Chem. Chem. Phys. 13 (45) (2011) 20215-20222.

[128] K. Hirsch, V. Zamudio-Bayer, J. Rittmann, et al., Phys. Rev. B 86 (16) (2012) 165402.

[129] H. Hu, J. Zuo, J. Wen, et al., N. J. Phys. 13 (2011) 053031.

[130] Z. Hu, G. Kaindl, S.A. Warda, et al., Chem. Phys. 232 (1-2) (1998) 63-74.

[131] Z. Hu, C. Mazumdar, G. Kaindl, et al., Chem. Phys. Lett. 297 (3-4) (1998) 321-328.

[132] N. Huse, T.K. Kim, L. Jamula, et al., J. Am. Chem. Soc. 132 (19) (2010) $6809-6816$
[133] N. Huse, H. Cho, K. Hong, et al., J. Phys. Chem. Lett. 2 (8) (2011) 880-884.

[134] S. Imada, T. Jo, J. Magn. Magn. Mater. 104 (1992) 2001-2002.

[135] S. Imada, T. Muro, S. Suga, et al., J. Electron Spectrosc. Relat. Phenom. 78 (1996) 279-282

[136] J.Jasinski, K.E. Pinkerton, I.M. Kennedy, et al., Microsc. Microanal. 12 (5)(2006) 424-431.

[137] C.K. Jorgensen, Spectroscopy of Transition-Group Complexes, Advanced in Chemical Physics 5, Wiley, 1963, chap. 2.

[138] J.S. Kaastra, C.P. de Vries, E. Constantini, et al., Astron. Astrophys. 497 (2009) 291-310.

[139] P. Kamp, A. Marty, B. Gilles, et al., Phys. Rev. B 59 (2) (1999) 1105-1112.

[140] V. Kanchana, G. Vaitheeswaran, M. Alouani, et al., Phys. Rev. B 75 (2007) 220404(R).

[141] J.S. Kang, G. Kim, H.J. Lee, et al., Phys. Rev. B 77 (3) (2008) 035121.

[142] J.S. Kang, H.J. Lee, G. Kim, et al., Phys. Rev. B 78. (5) (2008).

[143] T. Kataoka, M. Kobayashi, Y. Sakamoto, et al., J. Appl. Phys. 107 (3) (2010) 033718.

[144] R. Kelekar, H. Ohldag, B.M. Clemens, Phys. Rev. B Condens. Matter Mater. Phys. 75 (1) (2007)

[145] T. Kendelewicz, P. Liu, C. Doyle, et al., Surf. Sci. 469 (2-3) (2000) 144-163.

[146] T. Kendelewicz, P. Liu, C. Doyle, et al., Surf. Sci. 453 (1-3) (2000) 32-46.

[147] G. Kim, S.S. Lee, H.J. Lee, et al., J. Magn. Magn. Mater. 310(2)(2007)1969-1971.

[148] J.Y. Kim, T.Y. Koo, J.H. Park, Phys. Rev. Lett. 96 (4) (2006).

[149] M. Kitamura, S. Muramatsu, C. Sugiura, Phys. Rev. B 33 (8) (1986) 5294-5300

[150] S. Kiyono, S. Chiba, Y. Hayashi, et al., Jpn J. Appl. Phys. 17 (1978) 212-214.

[151] A. Kleibert, K.-. Meiwes-Broer, J. Bansmann, Phys. Rev. B Condens. Matter Mater. Phys. 79 (12) (2009).

[152] E.E. Koch, Y. Jugnet, F.J. Himpsel, Chem. Phys. Lett. 116 (1) (1985) 7-11.

[153] A. Koitzsch, R. Kraus, T. Kroll, et al., Phys. Rev. B 81 (17) (2010) 174519

[154] J. Kortright, S. Kim, Phys. Rev. B 62 (18) (2000) 12216-12228.

[155] S.A. Krasnikov, A.S. Vinogradov, A.B. Preobrajenski, et al., Phys. Scr. T115 (2005) 1074-1076

[156] G. Krill, J. Schille, M. Finazzi, et al., Nucl. Instrum. Meth. B 87 (1-4) (1994) $142-148$.

[157] K. Krishnan, Ultramicroscopy 32 (4) (1990) 309-311.

[158] O. Krivanek, J. Patterson, Ultramicroscopy 32 (4) (1990) 313-318

[159] T. Kroll, S. Bonhommeau, T. Kachel, et al., Phys. Rev. B 78 (22) (2008).

[160] T. Kroll, F. Roth, A. Koitzsch, et al., N. J. Phys. 11 (2009) 11.

[161] S. Kucas, A. Kyniene, R. Karazija, et al., J. Phys. Condens. Matter 17 (46) (2005) 7307-7318.

[162] K. Kuepper, M. Raekers, C. Taubitz, et al., J. Appl. Phys. 104 (2008) 036103.

[163] K. Kuepper, C. Taubitz, D. Taubitz, et al., J. Phys. Chem. Lett. 2 (13) (2011) 1491-1496.

[164] P. Kuiper, B.G. Searle, L.C. Duda, et al., J. Electron Spectrosc. Relat. Phenom. 86 (1-3) (1997) 107-113.

[165] P. Kuiper, B.G. Searle, P. Rudolf, et al., Phys. Rev. Lett. 70 (10) (1993) 1549-1552.

[166] Y. Kumagai, H. Ikeno, I. Tanaka, J. Phys. Condens. Matter 21 (2009) 104209.

[167] H. Kurata, K. Hojou, T. Uozumi, J. Electron Microsc. 47 (4) (1998) 293-299.

[168] E. Kurmaev, D. Zatsepin, S. Cholakh, et al., Phys. Solid State 47 (4) (2005) 754-757.

[169] E.Z. Kurmaev, J.A. McLeod, A. Buling, et al., Phys. Rev. B 80 (2009) 054508.

[170] E.Z. Kurmaev, J.A. McLeod, N.A. Skorikov, et al., J. Phys. Condens. Matter 21 (34) (2009) 345701

[171] E.Z. Kurmaev, J.A. McLeod, N.A. Skorikov, et al., J. Phys. Condens. Matter 21 (43) (2009) 435702

[172] K.D. Kwon, K. Refson, S. Bone, et al., Phys. Rev. B 83 (6) (2011) 064402.

[173] L. Laffont, C. Delacourt, P. Gibot, et al., Chem. Mater. 18 (23)(2006) 5520-5529.

[174] K.P. Lam, A.P. Hitchcock, M. Obst, et al., Chem. Geol. 270 (1-4)(2010) 110-116.

[175] J.T. Lau, A. Fohlisch, R. Nietubyc, et al., Phys. Rev. Lett. 89 (5) (2002).

[176] S. Lauterbach, C. McCammon, P. van Aken, et al., Contrib. Mineral. Petrol. 138 (1) (2000) 17-26

[177] R.D. Leapman, L.A. Grunes, P.L. Fejes, Phys. Rev. B 26 (2) (1982) 614.

[178] J.J. Lee, H.S. Sheu, C.R. Lee, et al., J. Am. Chem. Soc. 122 (24) (2000) 5742-5747.

[179] J. Lee, B. Ravel, Astrophys. J. 622 (2) (2005) 970-976.

[180] H.J. Lee, G. Kim, D.H. Kim, et al., J. Phys. Condens. Matter 20(29)(2008) 295203

[181] J.C. Lee, J. Xiang, B. Ravel, et al., Astrophys. J. 702 (2) (2009) 970-979.

[182] J.C. Lee, Space Sci. Rev. 157 (1-4) (2010) 93-101.

[183] I. Letard, P. Sainctavit, C. Deudon, Phys. Chem. Miner. 34 (2) (2007) 113-120

[184] I. Letard, P. Sainctavit, N. Menguy, et al., Phys. Scr. T115 (2005) 489-491.

[185] I. Letard, P. Sainctavit, C. Cartier dit Moulin, et al., J. Appl. Phys. 101 (11) (2007) 113920.

[186] A.B.P. Lever, E.I. Solomon, Inorg. Electron. Struct. Spectrosc. 1 (1999) 1-92.

[187] C. Li, L. Gu, S. Tsukimoto, et al., Adv. Mater. 22 (33) (2010), pp. 3650-+.

[188] M.T. Liu, S.C. Ray, H.M. Tsai, et al., J. Phys. Condens. Matter 20 (46) (2008) 465105.

[189] X. Liu, J. Liu, R. Qiao, et al., J. Am. Chem. Soc. 134 (33) (2012) 13708-13715

[190] Y. Lu, J. Claydon, Y. Xu, et al., Phys. Rev. B 70 (23) (2004) 233304.

[191] A.V. Lukoyanov, S.L. Skornyakov, J.A. McLeod, et al., Phys. Rev. B 81 (23) (2010) 235121.

[192] M. Mannini, F. Pineider, P. Sainctavit, et al., Adv. Mater. 21 (2)(2009) 167-171

[193] M. Mannini, F. Pineider, C. Danieli, et al., Nature 468 (7322) (2010) 417-421.

[194] M. Marangolo, F. Gustavsson, M. Eddrief, et al., Phys. Rev. Lett. 88 (21) (2002) 217202.

[195] L.W. Martin, Y. Chu, M.B. Holcomb, et al., Nano Lett. 8. (7) (2008). 
[196] M. Martins, K. Godehusen, T. Richter, et al., J. Phys. B At. Mol. Opt. Phys. 39 (2006) pR79-R125.

[197] S. Matzen, J.-. Moussy, R. Mattana, et al., Phys. Rev. B 83 (18) (2011) 184402.

[198] J.A. McLeod, A. Buling, R.J. Green, et al., J. Phys. Condens. Matter 24 (21) (2012) 215501.

[199] P.S. Miedema, S. Stepanow, P. Gambardella, et al., J. Phys. Conf. Ser. 190 (2009) 012143.

[200] Miedema, P.S. X-ray spectroscopy of inorganic materials, PhD thesis, Utrecht University, 2012.

[201] J. Miguel, C.F. Hermanns, M. Bernien, et al., J. Phys. Chem. Lett. 2 (12) (2011) 1455-1459.

[202] Y. Mikhlin, Y. Tomashevich, Phys. Chem. Miner. 32 (1) (2005) 19-27.

[203] J. Miot, K. Benzerara, G. Morin, et al., Geobiology 7 (3) (2009) 373-384.

[204] C. Mitterbauer, G. Kothleitner, W. Grogger, et al., Ultramicroscopy 96 (2003) 469-480.

[205] P. Morrall, F. Schedin, G. Case, et al., Phys. Rev. B 67 (21) (2003) 214408.

[206] J. Mosselmans, R. Pattrick, G. Vanderlaan, et al., Phys. Chem. Miner. 22 (5) (1995) 311-317.

[207] S. Mossin, B.L. Tran, D. Adhikari, et al., J. Am. Chem. Soc. 134 (33) (2012) 13651-13661.

[208] S. Nakai, K. Ogata, M. Ohashi, et al., J. Phys. Soc. Jpn. 54 (10) (1985) 4034-4041.

[209] K. Ogasawara, A. Chaya, S. Watanabe, et al., Int. J. Quantum Chem. 109 (2009) 2672-2676.

[210] J. Okamoto, K. Mamiya, S.I. Fujimori, et al., Phys. Rev. B 71. (10) (2005).

[211] K. Olejnik, P. Wadley, J.A. Haigh, et al., Phys. Rev. B 81 (10) (2010) 104402.

[212] E. Otero, P.O. Shipman, A.S. Abd-El-Aziz, et al., Organometallics 28 (7) (2009) 2160-2172.

[213] Y. Pan, G. Vaughan, R. Brydson, et al., Ultramicroscopy 110 (8) (2010) 1020-1032.

[214] R.A.D. Pattrick, G. Van der Laan, C.M.B. Henderson, et al., Eur. J. Mineral. 14 (6) (2002) 1095-1102.

[215] C.I. Pearce, C.M.B. Henderson, R.A.D. Pattrick, et al., Am. Mineral. 91 (5-6) (2006) 880-893.

[216] C.I. Pearce, C.M.B. Henderson, N.D. Telling, et al., Am. Mineral. 95 (4) (2010) 425-439.

[217] E. Pellegrin, M. Hagelstein, S. Doyle, et al., Phys. Status Solidi B Basic Res. 215 (1) (1999) 797-801.

[218] G. Peng, J. Vanelp, H. Jang, et al., J. Am. Chem. Soc. 117 (9) (1995) 2515-2519.

[219] N. Perez, F. Bartolome, L.M. Garcia, et al., Appl. Phys. Lett. 94 (9)(2009) 093108.

[220] V. Perez-Dieste, J.N. Crain, A. Kirakosian, et al., Phys. Rev. B 70 (2004) 085205.

[221] C. Piamonteze, P. Miedema, F.M.F. de Groot, Phys. Rev. B (Condensed Matter Mater. Phys.) 80 (18) (2009) 184410-184412.

[222] W.F. Pong, Y.K. Chang, M.H. Su, et al., Phys. Rev. B 55 (17)(1997) 11409-11413.

[223] N.R.J. Poolton, I.W. Kirkman, E. Pantos, J. Phys. D Appl. Phys. 44 (48) (2011) 485402.

[224] G. Radtke, S. Lazar, G.A. Botton, Phys. Rev. B 74 (15) (2006).

[225] T. Richter, K. Godehusen, M. Martins, et al., Phys. Rev. Lett. 93 (2) (2004) 023002.

[226] P. Rudolf, F. Sette, L.H. Tjeng, et al., J. Magn. Magn. Mater. 109 (1) (1992) $109-112$.

[227] P. Sainctavit, S. Brice-Profeta, E. Gaudry, et al., in: E. Beaurepaire, H. Bulou, F. Scheurer (Eds.), X-ray Spectroscopy and Magnetism in Mineralogy, 2006 (Retrieved 12.08.10).

[228] P. Schattschneider, S. Rubino, C. Hebert, et al., Nature 441 (7092) (2006) $486-488$.

[229] P. Schattschneider, M. Stoger-Pollach, S. Rubino, et al., Phys. Rev. B 78 (10) (2008).

[230] T. Schedel-Niedrig, W. Weiss, R. Schlogl, Phys. Rev. B 52 (24) (1995) 17449-17460.

[231] F. Schedin, E. Hill, G. van der Laan, et al., J. Appl. Phys. 96(2)(2004)1165-1169.

[232] F. Schedin, P. Morrall, V. Petrov, et al., J. Magn. Magn. Mater. 211 (1-3) (2000) 266-270.

[233] J. Schlappa, C. Schussler-Langeheine, C.F. Chang, et al., Phys. Rev. Lett. 100 (2008) 026406

[234] P. Schofield, G. Van der Laan, C. Henderson, et al., Mineral. Mag. 62 (1) (1998) 65-75.

[235] A. Scholl, J. Stohr, J. Luning, et al., Science 287 (5455) (2000) 1014-1016.

[236] C.F. Sheu, K. Chen, S.M. Chen, et al., Chem. A Eur. J. 15 (10) (2009) 2384-2393.

[237] L. Signorini, L. Pasquini, F. Boscherini, et al., Phys. Rev. B 74 (1) (2006) 014426.

[238] K. Soda, H. Murayama, S. Yagi, et al., Phys. B Condens. Matter 351 (3-4) (2004) 338-340.

[239] E.I. Solomon, C.B. Bell, Inorganic and Bioinorganic Spectroscopy, in: A. Bakac (Ed.), Physical Inorganic Chemistry: Principles, Methods, and Models, John Wiley \& Sons, Hoboken, USA, 2010.

[240] K.A. Simonov, A.S. Vinogradov, M.M. Brzhezinskaya, et al., Appl. Surf. Sci. 267 (2013) 132-135.

[241] P. Singh, Y.A. Park, K.D. Sung, et al., Solid State Commun. 150 (9-10) (2010).

[242] I.L. Soroka, M. Björck, R. Bručas, et al., Phys. Rev. B Condens. Matter Mater. Phys. 72 (13) (2005) 1-7.
[243] U. Staub, Y. Bodenthin, C. Piamonteze, et al., Phys. Rev. B 80 (14) (2009).

[244] E. Stavitski, F.M.F. de Groot, Micron 41 (2010) 687.

[245] S. Steinsvik, R. Bugge, J. Gjonnes, et al., J. Phys. Chem. Solids 58 (6) (1997) 969-976.

[246] S. Stepanow, P.S. Miedema, A. Mugarza, et al., Phys. Rev. B 83 (22) (2011) 220401.

[247] J. Stöhr, H. Konig, Phys. Rev. Lett. 75 (20) (1995) 3748-3751.

[248] J. Stöhr, R. Nakajima, IBM J. Res. Develop. 42 (1) (1998) 73-88.

[249] J. Tafto, O. Krivanek, Phys. Rev. Lett. 48 (8) (1982) 560-563.

[250] A.F. Takacs, M. Neumann, A.V. Postnikov, et al., J. Chem. Phys. 124 (2006) 044503.

[251] Y. Takagi, K. Isami, I. Yamamoto, et al., Phys. Rev. B Condens. Matter Mater. Phys. 81 (3) (2010).

[252] H. Tan, J. Verbeeck, A. Abakumov, et al., Ultramicroscopy (2012) 116.

[253] I. Tanaka, T. Mizoguchi, T. Yamamoto, J. Am. Ceram. Soc. 88 (8) (2005) 2013-2029.

[254] K. Tatsumi, S. Muto, I. Nishida, et al., Appl. Phys. Lett. 96 (20) (2010) 201911.

[255] C. Taubitz, K. Kuepper, M. Raekers, et al., Phys. Status Solidi B Basic Solid State Phys. 246 (7) (2009) 1470-1475.

[256] N.D. Telling, V.S. Coker, R.S. Cutting, et al., Appl. Phys. Lett. 95 (16) (2009) 163701.

[257] C. Teodorescu, F. Chevrier, R. Brochier, et al., Surf. Sci. 482 (2001) 1004-1009.

[258] B.T. Thole, G. van der Laan, P.H. Butler, Chem. Phys. Lett. 149 (3) (1988) 295-299.

[259] B.T. Thole, P. Carra, F. Sette, G. van der Laan, Phys. Rev. Lett. 68 (1992) p1943.

[260] S. Thuermer, R. Seidel, W. Eberhardt, et al., J. Am. Chem. Soc. 133 (32) (2011) $12528-12535$

[261] A.N. Titov, Y.M. Yarmoshenko, P. Bazylewski, et al., Chem. Phys. Lett. 497 (4-6) (2010) 187-190.

[262] E. Todd, D. Sherman, J. Purton, Geochim. Cosmochim. Acta 67 (12) (2003) 2137-2146.

[263] Y.-. Tseng, N.M. Souza-Neto, D. Haskel, et al., Phys. Rev. B 79 (2009) 094404

[264] S. Turner, J. Verbeeck, F. Ramezanipour, et al., Chem. Mater. 24 (10) (2012).

[265] P. van Aken, B. Liebscher, V. Styrsa, Phys. Chem. Miner. 25 (5) (1998) 323-327.

[266] P.A. van Aken, B. Liebscher, Phys. Chem. Miner. 29 (3) (2002) 188-200.

[267] P.A. van Aken, S. Lauterbach, Phys. Chem. Miner. 30 (8) (2003) 469-477.

[268] G. van der Laan, B.T. Thole, Phys. Rev. B 43 (16) (1991) 13401-13411.

[269] G. van der Laan, I. Kirkman, J. Phys. Condens. Matter 4 (16) (1992) 4189-4204

[270] G. van der Laan, P. Schofield, G. Cressey, et al., Chem. Phys. Lett. 252 (3-4) (1996) 272-276

[271] van der Laan, Lect. Notes Phys. 697 (2006) 143-199.

[272] J. van Elp, G. Peng, Z.H. Zhou, et al., Phys. Rev. B 53 (5) (1996) 2523-2527.

[273] L. Vayssieres, C. Sathe, S. Butorin, et al., Adv. Mater. 17 (19) (2005), pp. 2320-+

[274] A. Vinogradov, A. Preobrajenski, A. Knop-Gericke, et al., J. Electron Spectrosc. Relat. Phenom. 114 (2001) 813-818.

[275] A.S. Vinogradov, A.B. Preobrajenski, S.A. Krasnikov, et al., Surf. Rev. Lett. 9 (1) (2002) 359-364.

[276] J. Vogel, M. Sacchi, R. Kappert, et al., J. Magn. Magn. Mater. 150 (3) (1995) 293-303.

[277] H. Wang, G. Peng, L. Miller, et al., J. Am. Chem. Soc. 119 (21) (1997) 4921-4928.

[278] H.X. Wang, G. Peng, S.P. Cramer, J. Electron Spectrosc. Relat. Phenom. 143 (1) (2005) 1-7.

[279] F. Wang, R.F. Egerton, M. Malac, Ultramicroscopy 106 (2006) 925-932.

[280] J. Wang, N. Ji, X. Liu, et al., IEEE Trans. Magnet. 48 (5) (2012) 1710-1717.

[281] E.C. Wasinger, F.M.F. de Groot, B. Hedman, et al., J. Am. Chem. Soc. 125 (42) (2003) 12894-12906.

[282] A.T. Wen, E. Ruhl, A.P. Hitchcock, Organometallics 11 (7) (1992) 2559-2569.

[283] H. Wende, Rep. Prog. Phys. 67 (12) (2004) 2105-2181.

[284] H. Wende, M. Bernien, J. Luo, et al., Nat. Mater. 6 (7) (2007) 516-520.

[285] Y. Xu, M. Tselepi, C. Guertler, et al., J. Appl. Phys. 89 (11) (2001) 7156-7158.

[286] S. Yang, D. Wang, G. Liang, et al., Energy Environ. Sci. 5 (5) (2012) 7007-7016.

[287] T. Yamaguchi, S. Shibuya, S. Suga, et al., J. Phys. C Solid State Phys. 15 (12) (1982) 2641-2650.

[288] F. Yildiz, F. Luo, C. Tieg, et al., Phys. Rev. Lett. 100 (3) (2008).

[289] P. Yu, J. Lee, S. Okamoto, et al., Phys. Rev. Lett. 105 (2) (2010) 027201.

[290] T. Zega, L. Garvie, P. Buseck, Am. Mineral. 88 (7) (2003) 1169-1172.

[291] T. Zhao, A. Scholl, F. Zavaliche, et al., Appl. Phys. Lett. 90 (12) (2007) 123104

[292] D. Asakura, M. Okubo, Y. Mizuno, et al., Phys. Rev. B 84 (2011) 045117.

[293] J.F. Peters, J. Miguel, M.A. de Vries, et al., Phys. Rev. B 70 (2004) 224417.

[294] T. Ueno, M. Sawada, K. Furumoto, et al., Phys. Rev. B 85 (2012) 224406.

[295] J.A. Moyer, C.A.F. Vaz, D.P. Kumah, et al., Phys. Rev. B 86 (2012) 174404.

[296] T. Higuchi, Y.-S. Liu, P. Yao, et al., Phys. Rev. B 78 (2008) 085106.

[297] T. Higuchi, T. Hattori, W. Sakamoto, et al., Jpn. J. Appl. Phys. 47 (2008). 